\title{
Thermodynamic characterization of Mexico City aerosol during MILAGRO 2006
}

\author{
C. Fountoukis ${ }^{1, *}$, A. Nenes ${ }^{1,2}$, A. Sullivan ${ }^{2, * *}$, R. Weber ${ }^{2}$, T. Van Reken ${ }^{3, * * *}$, M. Fischer ${ }^{4}$, E. Matías ${ }^{5}$, M. Moya ${ }^{5}$, \\ D. Farmer ${ }^{6}$, and R. C. Cohen ${ }^{6}$ \\ ${ }^{1}$ School of Chemical \& Biomolecular Engineering, Georgia Institute of Technology, Atlanta, GA, USA \\ ${ }^{2}$ School of Earth \& Atmospheric Sciences, Georgia Institute of Technology, Atlanta, GA, USA \\ ${ }^{3}$ National Center for Atmospheric Research, Boulder, CO, USA \\ ${ }^{4}$ Environmental Energy Technologies Division, Lawrence Berkeley National Laboratory, Berkeley, CA, USA \\ ${ }^{5}$ Centro de Ciencias de la Atmosfera, Universidad Nacional Autonoma de Mexico, Mexico City, Mexico \\ ${ }^{6}$ Department of Chemistry, University of California Berkeley, Berkeley, CA, USA \\ *now at: Institute of Chemical Engineering and High Temperature Chemical Processes (ICEHT), Foundation for Research \\ and Technology Hellas (FORTH), Patras, Greece \\ ${ }^{* *}$ now at: Department of Atmospheric Science, Colorado State University, Fort Collins, CO, USA \\ **** now at: Laboratory for Atmospheric Research, Department of Civil \& Environmental Engineering, Washington State \\ University, Pullman, Washington, USA
}

Received: 30 May 2007 - Published in Atmos. Chem. Phys. Discuss.: 28 June 2007

Revised: 8 December 2008 - Accepted: 20 February 2009 - Published: 24 March 2009

\begin{abstract}
Fast measurements of aerosol and gas-phase constituents coupled with the ISORROPIA-II thermodynamic equilibrium model are used to study the partitioning of semivolatile inorganic species and phase state of Mexico City aerosol sampled at the T1 site during the MILAGRO 2006 campaign. Overall, predicted semivolatile partitioning agrees well with measurements. $\mathrm{PM}_{2.5}$ is insensitive to changes in ammonia but is to acidic semivolatile species. For particle sizes up to $1 \mu \mathrm{m}$ diameter, semi-volatile partitioning requires $15-30 \mathrm{~min}$ to equilibrate; longer time is typically required during the night and early morning hours. Aerosol and gas-phase speciation always exhibits substantial temporal variability, so that aerosol composition measurements (bulk or size-resolved) obtained over large integration periods are not reflective of its true state. When the aerosol sulfate-to-nitrate molar ratio is less than unity, predictions improve substantially if the aerosol is assumed to follow the deliquescent phase diagram. Treating crustal species as "equivalent sodium" (rather than explicitly) in the thermodynamic equilibrium calculations introduces important biases in predicted aerosol water uptake, nitrate and ammonium; neglecting crustals further increases errors dramati-
\end{abstract}

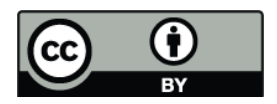

Correspondence to: A. Nenes (athanasios.nenes@gatech.edu) cally. This suggests that explicitly considering crustals in the thermodynamic calculations is required to accurately predict the partitioning and phase state of aerosols.

\section{Introduction}

Atmospheric particulate matter plays a central role in atmospheric phenomena like visibility reduction, public health, formation of acid rain and climate change. Fine particles, otherwise called $\mathrm{PM}_{2.5}$ (particles with diameter less than $2.5 \mu \mathrm{m}$ ) are prime contributors to the above processes, a quantitative understanding of which requires knowledge of their phase and composition. Much of the dry particle mass is inorganic (25-75\%) (Heitzenberg, 1989) with the main components often being ammonium $\left(\mathrm{NH}_{4}^{+}\right)$, sulfate $\left(\mathrm{SO}_{4}^{2-}\right)$, and nitrate $\left(\mathrm{NO}_{3}^{-}\right)$. Depending on the location, sodium $\left(\mathrm{Na}^{+}\right)$ and chloride $\left(\mathrm{Cl}^{-}\right)$may also be found as well as crustal species $\left(\mathrm{Ca}^{2+}, \mathrm{K}^{+}, \mathrm{Mg}^{2+}\right)$ which are associated with dust (Heitzenberg, 1989; Malm et al., 1994). These species may be dissolved in the aqueous phase, or in the form of precipitated solids, and some may partially volatilize (e.g $\mathrm{NH}_{3}$, $\mathrm{HNO}_{3}, \mathrm{HCl}$ ). The partitioning of these species between gas, liquid and solid phase is determined by dynamical processes (e.g condensation/evaporation), which, if fast enough lead to thermodynamic equilibrium and can be simulated

Published by Copernicus Publications on behalf of the European Geosciences Union. 
by aerosol equilibrium models, such as AIM2 (Wexler and Clegg, 2002), SCAPE2 (Meng et al., 1995), GFEMN (Ansari and Pandis, 1999a, b), UHAERO (Amundson et al., 2006) and ISORROPIA-II (Fountoukis and Nenes, 2007). These models differ in the chemical species that they can treat, the method used to solve for equilibrium composition, the type of input they can accept, and their computational efficiency. Similarities and differences between these models are discussed elsewhere (e.g., Ansari and Pandis, 1999a, b; Zhang et al., 2000; Amundson et al., 2006; Fountoukis and Nenes, 2007).

An important question is whether equilibrium models (all of which embody simplified representations of aerosol composition) can adequately predict the equilibrium partitioning of semivolatile inorganic species. This is often assessed by comparing model predictions against measurements, assuming thermodynamic equilibrium applies between the aerosol and gas phases. Equilibrium partitioning of semi-volatile species is often assumed in online aerosol simulations, therefore another important issue is understanding when it can be used. A key factor is aerosol size (Wexler and Seinfeld 1991, 1992; Meng and Seinfeld, 1996; Dassios and Pandis, 1999; Cruz et al., 2000); for submicron particles, equilibrium is achieved typically within a few minutes, often faster than the timescale of ambient condition change (Meng and Seinfeld, 1996; Dassios and Pandis, 1999; Cruz et al., 2000) so that the assumption of instantaneous equilibrium can be used to model composition. Coarse mode particles however require substantial time, on the order of an hour or more (Meng and Seinfeld, 1996; Dassios and Pandis, 1999; Cruz et al., 2000), so explicit condensation/evaporation dynamics is required for modeling composition (e.g., Pilinis et al., 2000; Capaldo et al., 2000). Capaldo et al. (2000) found that application of bulk equilibrium is adequate for particles up to $1 \mu \mathrm{m}$ diameter; larger particles require modeling using a dynamical approach.

Several studies have been conducted to concurrently test the applicability of the equilibrium assumption and model prediction skill by comparing thermodynamic model predictions against observational data. Moya et al. (2001) used ISORROPIA, SCAPE2 and GFEMN to study the partitioning of nitrate and ammonium in Mexico City during the 1997 IMADA-AVER field campaign. Using daily and 6-h average $\mathrm{PM}_{2.5}$ data, Moya et al. (2001) found the equilibrium approach reproduced most of the data, however a few discrepancies were found and were attributed to the implicit treatment of crustal species (treated as "equivalent" sodium by ISORROPIA and GFEMN) as opposed to the explicit treatment (by SCAPE2) and to the use of IMADA observations averaged over long periods of time $(6 \mathrm{~h})$. Zhang et al. (2003) assessed the nitrate - ammonium equilibrium assumption using the ISORROPIA model and high resolution (5-min average) data obtained during the 1999 Atlanta Supersite Experiment. They found good agreement for nitrate and ammonium when a $15 \%$ correction (within measurement uncer- tainty) in $\mathrm{PM}_{2.5} \mathrm{SO}_{4}^{2-}$ was applied. Takahama et al. (2004) used GFEMN to model the partitioning of nitrate during the 2001-2002 Pittsburg Air Quality Study (PAQS). Using 1 and 2-hour average measurements of $\mathrm{PM}_{2.5}$ they found most of the predictions of nitrate to agree with observations to within experimental uncertainty. Other factors can also influence the agreement with observations. Yu et al. (2005) used the 1999 Atlanta Supersite Experiment data, the PAQS dataset, and 12-h measurement data from North Carolina in 1999 to assess the ability of the three-dimensional (3-D) Community Multiscale Air Quality (CMAQ) model (which includes ISORROPIA) to predict aerosol nitrate. They found that errors associated with sulfate and total ammonium predictions of the 3-D model can lead to large errors in predicted aerosol nitrate. Metzger et al. (2006) used ISORROPIA, SCAPE2 and EQSAM2 to study the partitioning of ammonium and nitrate during the Mediterranean INtensive Oxidant Study (MINOS) experiment. Using 2 and $3 \mathrm{~h}$ average measurements they showed that only when crustal species and (lumped) organic acids are explicitly accounted for, the observed gas aerosol partitioning of ammonia and nitric acid can be accurately reproduced. Using CMAQ and ISORROPIA, Nowak et al. (2006) analyzed gas phase ammonia measurements (using a PILS for the aerosol and a CIMS instrument for the gas phase data) from the 2002 Atlanta Aerosol Nucleation and Real-Time Characterization Experiment (ANAR$\mathrm{ChE}$ ) and found excellent agreement for $\mathrm{NH}_{3}$ and $\mathrm{NH}_{4}^{+}$concentrations.

The phase state of aerosols is another important issue in aerosol modeling, as they can follow the deliquescence branch (in which solids precipitate out of the aqueous aerosol phase upon saturation) or the metastable branch (in which the aerosol is always an aqueous phase and solids are not allowed to form). Phase state may depend on RH history. For example, as RH increases, particles deliquesce, while when RH decreases, a particle may not crystallize at its initial deliquescence point, but retain water until a much lower relative humidity (known as the hysteresis phenomenon). Ansari and Pandis (2000) studied the impact of assuming a deliquescent vs. metastable path on the partitioning of nitrate in Southern California; when nitrate concentrations were low $\left(<8 \mu \mathrm{g} \mathrm{m}^{-3}\right)$, the considerations of both branches of aerosol behavior is essential, while no significant difference between stable and metastable predictions was found for high $\left(>8 \mu \mathrm{g} \mathrm{m}^{-3}\right)$ aerosol nitrate concentrations. Moya et al. (2002) showed that the assumption of metastable state for sub-micrometer particles may introduce large errors when $\mathrm{RH}<60 \%$, highlighting the importance of deliquescence predictions at low RH.

Most studies to date either use measurements averaged over long times or use models that do not explicitly treat crustals. If measurements are slow, significant variations in $T$, RH and aerosol precursor concentrations may occur during sampling which cannot be accounted for in equilibrium calculations. Additionally, the consideration of crustal 
material in predicting the partitioning of nitrate and ammonium, especially in areas where dust comprises a significant portion of total PM, can affect the aerosol thermodynamics and improve model prediction skill (Ansari and Pandis, 1999; Moya et al., 2002).

In the present work, we use ISORROPIA-II, which treats the thermodynamics of the $\mathrm{K}^{+}-\mathrm{Ca}^{2+}-\mathrm{Mg}^{2+}-\mathrm{NH}_{4}^{+}$$\mathrm{Na}^{+}-\mathrm{SO}_{4}^{2-}-\mathrm{HSO}_{4}^{-}-\mathrm{NO}_{3}^{-}-\mathrm{Cl}^{-}-\mathrm{H}_{2} \mathrm{O}$ aerosol system, to a) concurrently test the model prediction skill and thermodynamic equilibrium assumption for the Mexico City aerosol during the MILAGRO 2006 campaign, b) gain insight on the preferred phase behavior of the aerosol (i.e. deliquescent or metastable) and equilibration timescale, and, c) assess the importance of neglecting crustal species (or treating them as equivalent sodium) in thermodynamic calculations. The MILAGRO 2006 dataset analyzed here is ideal for the objectives of this study, because of significant concentrations of all the inorganic species mentioned above.

\section{Observational data}

The Megacity Initiative: Local and Global Research Observations (MILAGRO) Campaign took place in 1-30 March 2006 (http://www.eol.ucar.edu/projects/milagro/). The three main ground locations were: one site at the Instituto Mexicano del Petróleo (T0 site, latitude: $19.25 \mathrm{~N}$, longitude: $99.10 \mathrm{~W}$ ), another at the Universidad Tecnológica de Tecámac in the State of Mexico (T1 site, latitude: $19.703 \mathrm{~N}$, longitude: $98.982 \mathrm{~W}$ ) and a third in Rancho La Bisnaga in the State of Hidalgo (T2 site, latitude: $20.01 \mathrm{~N}$, longitude: $98.909 \mathrm{~W})$. The data analyzed in this study were collected at the T1 site from 21 to 30 March 2006 and include fine particulate matter concentrations $\left(\mathrm{PM}_{2.5}\right)$ of $\mathrm{NH}_{4}^{+}, \mathrm{SO}_{4}^{2-}, \mathrm{NO}_{3}^{-}$, $\mathrm{Na}^{+}, \mathrm{Cl}^{-}, \mathrm{Ca}^{2+}, \mathrm{K}^{+}, \mathrm{Mg}^{2+}$, gas phase concentrations of $\mathrm{NH}_{3}, \mathrm{HNO}_{3}$ and ambient temperature, and relative humidity.

The $\mathrm{PM}_{2.5}$ ion concentrations were measured by a Particle Into Liquid Sampler (PILS) with a 6-min integrated sampling period and a new chromatogram being started every 17 min (Orsini et al., 2003). The advantage of this instrument is the simultaneous measurements of important inorganic anions and cations at high time-resolution. $\mathrm{NH}_{3(\mathrm{~g})}$ concentrations were obtained every minute with quantumcascade laser (QCL) spectrometer, while volatile nitrate (i.e. $\mathrm{HNO}_{3(\mathrm{~g})}+\mathrm{NH}_{4} \mathrm{NO}_{3}$ ) concentrations were measured every $5 \mathrm{~min}$ by a thermal dissociation-laser induced fluorescence of nitrogen oxides (TD-LIF, Day et al., 2002; Farmer et al., 2006). Ambient temperature ( $T$ ), pressure and relative humidity (RH) data are based on the measurements of the Vaisala Y50 Sensor which was operated with a 1-min time resolution. Aerosol particles ( $\left.\mathrm{PM}_{2.5}\right)$ were also collected (6$\mathrm{h}$ samples) with filters at the same site and sampling period.

6-min averages of $\mathrm{NH}_{3(\mathrm{~g})}$ concentrations, $T$ and $\mathrm{RH}$ were obtained to correspond to the 5-min averages of $\mathrm{HNO}_{3}(\mathrm{~g})$ and 6-min averages of $\mathrm{PM}_{2.5}$ ion concentrations. In $\sim 26 \%$ of the cases, the 5-min averages of $\mathrm{HNO}_{3(\mathrm{~g})}$ data were not coincident with the 6-min PILS concentrations, therefore a $\sim 20$-min average was considered instead (average of two measurements with a 10-min interval between the two data points). The TD-LIF measurement is the sum of gas-phase and semivolatile nitrate (i.e. $\mathrm{HNO}_{3(\mathrm{~g})}+\mathrm{NH}_{4} \mathrm{NO}_{3}$ ), from which $\mathrm{HNO}_{3(\mathrm{~g})}$ is obtained by subtracting $\mathrm{PM}_{2.5}$ ammonium nitrate concentrations from the PILS; this can be done because preliminary ISORROPIA-II calculations suggest that the PILS nitrate is entirely semivolatile (i.e. $\mathrm{NH}_{4} \mathrm{NO}_{3}$ only). Aerosol $\mathrm{K}^{+}$was not accurately measured by PILS due to a calibration interference; instead, it was estimated based on a nearly constant ratio $(\sim 0.4)$ of $\mathrm{K}^{+}$to the sum of crustal species $\left(\mathrm{Ca}^{2+}, \mathrm{K}^{+}, \mathrm{Mg}^{2+}\right)$ obtained from the impactor data for the same site and sampling period. Gas-phase hydrochloric acid $\left(\mathrm{HCl}_{(g)}\right)$ concentrations were assumed to be zero (hence total $\mathrm{Cl}^{-}$was equal to aerosol $\mathrm{Cl}^{-}$). The validity of this assumption is assessed in Sect. 4. The measurement uncertainty was estimated to be approximately $\pm 20 \%$ for the PILS instrument (Orsini et al., 2003), $\pm 10 \%$ for the $\mathrm{NH}_{3(\mathrm{~g})}$ measurement, $\pm 30 \%$ for the TD-LIF instrument (Day et al., 2002; Farmer et al., 2006) and $\pm 5 \%$ for $\mathrm{RH}$. The $\mathrm{HNO}_{3(\mathrm{~g})}$ uncertainty, $\sigma_{\mathrm{HNO}_{3(\mathrm{~g})}}$, was estimated from the uncertainties of volatile and PILS nitrate, $\sigma_{\mathrm{TD}-\mathrm{LIF}}$ nitrate and $\sigma_{\mathrm{PILS}}$ nitrate, respectively, as:

$\sigma_{\mathrm{HNO}_{3(\mathrm{~g})}}^{2}=\sigma_{(\mathrm{TD}-\mathrm{LIF} \text { nitrate) }}^{2}+\sigma_{(\mathrm{PILS} \text { nitrate) }}^{2}$

The reported detection limit for the PILS concentrations is $0.02 \mu \mathrm{g} \mathrm{m}^{-3}$ for PILS $\mathrm{Na}^{+}, \mathrm{NH}_{4}^{+}, \mathrm{NO}_{3}^{-}$and $\mathrm{SO}_{4}^{2-}, 0.002 \mu \mathrm{g} \mathrm{m}^{-3}$ for PILS $\mathrm{Ca}^{2+}, \mathrm{Mg}^{2+}$ and $\mathrm{Cl}^{-}$and $0.35 \mu \mathrm{g} \mathrm{m}^{-3}$ for the QCL NH $\mathrm{N}_{3(\mathrm{~g})}$ measurement.

Overall, 102 6-min data points were obtained for which measurements of all particulate and gaseous species are available. Ammonia was predominantly in the gas phase while nitrate was mostly in the aerosol phase. The total (gas+particulate) ammonia (TA) to sulfate molar ratio was much larger than 2 (average value $=26.5$ ) indicating sulfate poor aerosols. Relatively low concentrations of $\mathrm{Na}^{+}$ $\left(0.063 \pm 0.113 \mu \mathrm{g} \mathrm{m}^{-3}\right), \mathrm{Ca}^{2+}\left(0.116 \pm 0.206 \mu \mathrm{g} \mathrm{m}^{-3}\right), \mathrm{K}^{+}$ $\left(0.097 \pm 0.140 \mu \mathrm{g} \mathrm{m}^{-3}\right)$ and $\mathrm{Mg}^{2+}\left(0.033 \pm 0.051 \mu \mathrm{g} \mathrm{m}^{-3}\right)$ were detected while the total $\mathrm{PM}_{2.5}$ mass was, on average, $28.47 \pm 13.03 \mu \mathrm{g} \mathrm{m}^{-3}$. Temperature did not vary significantly over the measurement period of study (mean value of $289.5 \pm 5.1 \mathrm{~K}$ ) while RH varied significantly (mean value of $58.1 \pm 22.6 \%$ ), exhibiting a typical diurnal cycle which peaks in the evening and early morning and is minimum at around noon. Figure 1 shows an example of diurnal profiles of measured ammonium, nitrate and ambient RH for 27 March. A detailed overview of the dataset and meteorological conditions is given elsewhere (e.g. Doran et al., 2007; Fast et al., 2007). 


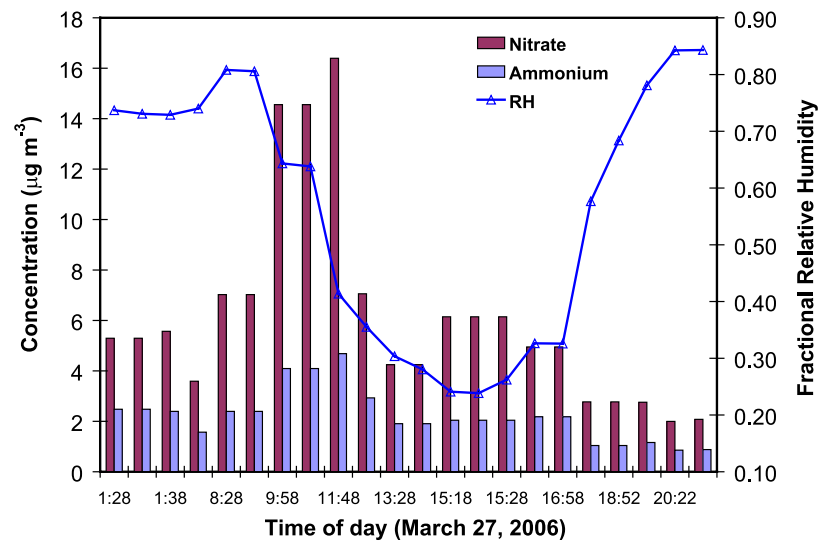

Fig. 1. Diurnal profile of measured nitrate, ammonium and ambient RH for 27 March 2006.

\section{Aerosol equilibrium modeling}

ISORROPIA-II (Fountoukis and Nenes, 2007) is a computationally efficient code that treats the thermodynamics of $\mathrm{K}^{+}$$\mathrm{Ca}^{2+}-\mathrm{Mg}^{2+}-\mathrm{NH}_{4}^{+}-\mathrm{Na}^{+}-\mathrm{SO}_{4}^{2-}-\mathrm{NO}_{3}^{-}-\mathrm{Cl}^{-}-\mathrm{H}_{2} \mathrm{O}$ aerosol systems and is used in this study. ISORROPIA-II is designed to solve two classes of problems: (a) forward (or "closed") problems, in which known quantities are $T, \mathrm{RH}$ and the total (gas + aerosol) concentrations of $\mathrm{NH}_{3}, \mathrm{H}_{2} \mathrm{SO}_{4}, \mathrm{Na}^{+}$, $\mathrm{HCl}, \mathrm{HNO}_{3}, \mathrm{Ca}^{2+}, \mathrm{K}^{+}$, and $\mathrm{Mg}^{2+}$, and, (b) reverse (or "open") problems, in which known quantities are $T, \mathrm{RH}$ and the concentrations of aerosol $\mathrm{NH}_{4}^{+}, \mathrm{SO}_{4}^{2-}, \mathrm{Na}^{+}, \mathrm{Cl}^{-}$, $\mathrm{NO}_{3}^{-}, \mathrm{Ca}^{2+}, \mathrm{K}^{+}$, and $\mathrm{Mg}^{2+}$. The output of both problems is the concentration of species in gas and aerosol (solid/liquid) phase. ISORROPIA-II can predict composition for the "stable" (or deliquescent path) solution where salts precipitate once the aqueous phase becomes saturated with respect to a salt, and, a "metastable" solution, in which the aerosol is composed only of an aqueous phase regardless of its saturation state. For the dataset of this study, the forward mode of ISORROPIA-II is used.

Given that there are no size-resolved data available with a temporal resolution of minutes, applying a size-resolved analysis would require numerous assumptions that would introduce rather important uncertainties. Instead, a bulk equilibrium assumption is used; although this can often lead to large prediction errors (as composition across particle sizes tend to vary), we postulate that it is a reasonable assumption for submicron Mexico City aerosol for the following reasons:

- Mexico City is unusually ammonia-rich. Most of $\mathrm{NH}_{3}$ resides in the gas phase even after equilibration, hence particle acidity is not expected to vary substantially with size.

- Aerosol at the T1 site is often aged, hence tends to be internally mixed.
- Submicron aerosol mass in Mexico City tends to be in the 300-900 nm range (e.g., Salcedo et al., 2006), hence the equilibrium assumption can be used for those particles (Capaldo et al., 2000).

\section{Results and discussion}

\subsection{Model vs. observations}

In this section we evaluate the ability of ISORROPIA-II to reproduce the observed partitioning of ammonia, nitrate and chloride, which will test the expectation that equilibrium partitioning of semivolatile aerosol species is attained somewhere between 6 and $30 \mathrm{~min}$. Figure 2a-e shows predicted vs. observed concentrations of gas-phase ammonia $\left(\mathrm{NH}_{3(\mathrm{~g})}\right)$, nitric acid $\left(\mathrm{HNO}_{3(\mathrm{~g})}\right)$, aerosol phase ammonium $\left(\mathrm{NH}_{4(p)}\right)$, nitrate $\left(\mathrm{NO}_{3(p)}\right)$ and chloride $\left(\mathrm{Cl}_{(p)}\right)$, respectively; Table 1 summarizes the corresponding error metrics. For the simulations of Fig. 2, ISORROPIA-II was run in forward mode and stable state conditions. Most of the total ammonia $(88.7 \%$ on average) resides in the gas phase. The data have been separated into 4 classes based on a "completeness factor" (CF). For half of the data analyzed (51\%), 6-min average measurements of all (gas+particulate phase) species were available; these data are represented as " $\mathrm{CF}=0$ ". For $\sim 26 \%$ of the data, only 20-min average (two 6-min averages with a 10-min interval) measurement of ion concentrations from the PILS instrument were available and are " $\mathrm{CF}=1$ " data. Subtracting the PILS ammonium nitrate measurement from the TD-LIF (i.e. $\mathrm{HNO}_{3(\mathrm{~g})}+\mathrm{NH}_{4} \mathrm{NO}_{3}$ ) occasionally resulted in a negative $\mathrm{HNO}_{3(\mathrm{~g})}$. Under such conditions, $\mathrm{HNO}_{3(\mathrm{~g})}$ is assumed zero, and the data is indicated as " $\mathrm{CF}=2$ " if they correspond to 6-min averages ( $13 \%$ of the data), and " $\mathrm{CF}=3$ " for $20 \mathrm{~min}$ averages (10\% of the data). The prediction skill of ISORROPIA-II is quantified in terms of five error metrics, the normalized mean error (NME), NME $=\frac{\sum_{i}^{n}\left|I_{i}-O_{i}\right|}{\sum_{i}^{n} O_{i}}$, the normalized mean bias (NMB), NMB $=\frac{\sum_{i}^{n}\left(I_{i}-O_{i}\right)}{\sum_{i}^{n} o_{i}}$, the mean absolute gross error (MAGE), MAGE $=\frac{1}{N} \sum_{i}^{n}\left|I_{i}-O_{i}\right|$, the mean bias (MB), $\mathrm{MB}=\frac{1}{N} \sum_{i}^{n}\left(I_{i}-O_{i}\right)$, and the root mean square error (RMSE), RMSE $=\left[\frac{1}{N} \sum_{i}^{n}\left(I_{i}-O_{i}\right)^{2}\right]^{1 / 2}$, where $I_{i}$ represents predictions of ISORROPIA-II for data point $i, O_{i}$ represents the corresponding observations and $n$ is the total number of data points. NME and MAGE give an estimation of the overall discrepancy (scatter) between predictions and observations, while NMB and MB are sensitive to systematic errors (biases). MAGE and MB give the error and bias 
Table 1. Comparison between predicted and observed concentrations of semivolatile species during the MILAGRO 2006 (21-30 March) campaign. Simulations are done assuming the aerosol can form solids ("stable" solution).

\begin{tabular}{|c|c|c|c|c|c|c|c|}
\hline Data Type & Quantity & $\mathrm{NH}_{3}(\mathrm{~g})$ & $\mathrm{NH}_{4(p)}$ & $\mathrm{HNO}_{3}(\mathrm{~g})$ & $\mathrm{NO}_{3}(p)$ & $\mathrm{HCl}_{(g)}$ & $\mathrm{Cl}_{(p)}$ \\
\hline \multirow{8}{*}{$\begin{array}{l}\text { All data } \\
\text { (102 data) }\end{array}$} & mean observed $\left(\mu \mathrm{g} \mathrm{m}^{-3}\right)$ & $17.73 \pm 11.02$ & $2.24 \pm 1.22$ & $1.81 \pm 1.88$ & $5.37 \pm 3.57$ & - & $0.25 \pm 0.56$ \\
\hline & mean predicted $\left(\mu \mathrm{g} \mathrm{m}^{-3}\right)$ & $16.89 \pm 10.97$ & $3.08 \pm 1.56$ & $1.38 \pm 1.92$ & $5.8 \pm 3.86$ & $0.03 \pm 0.11$ & $0.22 \pm 0.55$ \\
\hline & $\operatorname{NME}(\%)$ & 5.3 & 42.0 & 80.9 & 27.2 & - & 15.6 \\
\hline & NMB (\%) & -4.7 & 37.1 & -23.8 & 8.0 & - & -15.6 \\
\hline & $\operatorname{MAGE}\left(\mu \mathrm{g} \mathrm{m}^{-3}\right)$ & 0.94 & 0.94 & 1.46 & 1.46 & - & 0.04 \\
\hline & $\operatorname{MB}\left(\mu \mathrm{g} \mathrm{m}^{-3}\right)$ & -0.83 & 0.83 & -0.43 & 0.43 & - & 0.04 \\
\hline & $\operatorname{RMSE}\left(\mu \mathrm{g} \mathrm{m}^{-3}\right)$ & 1.27 & 1.27 & 2.02 & 2.02 & - & 0.12 \\
\hline & mean observed $\left(\mu \mathrm{g} \mathrm{m}^{-3}\right)$ & $17.33 \pm 9.83$ & $2.37 \pm 1.18$ & $2.63 \pm 1.87$ & $5.57 \pm 3.50$ & - & $0.28 \pm 0.56$ \\
\hline \multirow{7}{*}{$\begin{array}{l}\mathrm{CF}=0 \\
\text { (51 data) }\end{array}$} & mean predicted $\left(\mu \mathrm{g} \mathrm{m}^{-3}\right)$ & $16.16 \pm 9.88$ & $3.54 \pm 1.57$ & $1.43 \pm 1.98$ & $6.76 \pm 3.77$ & $0.04 \pm 0.12$ & $0.25 \pm 0.55$ \\
\hline & NME $(\%)$ & 7.2 & 52.3 & 71.7 & 33.9 & - & 17.6 \\
\hline & NMB (\%) & -6.7 & 49.2 & -45.5 & 21.5 & - & -17.6 \\
\hline & $\operatorname{MAGE}\left(\mu \mathrm{g} \mathrm{m}^{-3}\right)$ & 1.24 & 1.24 & 1.89 & 1.89 & - & 0.05 \\
\hline & $\mathrm{MB}\left(\mu \mathrm{g} \mathrm{m}^{-3}\right)$ & -1.17 & 1.17 & -1.20 & 1.20 & - & -0.05 \\
\hline & $\operatorname{RMSE}\left(\mu \mathrm{g} \mathrm{m}^{-3}\right)$ & 1.61 & 1.61 & 2.49 & 2.49 & 0.13 & 0.08 \\
\hline & mean observed $\left(\mu \mathrm{g} \mathrm{m}^{-3}\right)$ & $17.05 \pm 12.38$ & $1.83 \pm 0.84$ & $1.86 \pm 1.64$ & $3.88 \pm 1.99$ & - & $0.10 \pm 0.30$ \\
\hline \multirow{7}{*}{$\begin{array}{l}\mathrm{CF}=1 \\
(26 \text { data })\end{array}$} & mean predicted $\left(\mu \mathrm{g} \mathrm{m}^{-3}\right)$ & $16.49 \pm 12.23$ & $2.39 \pm 1.07$ & $1.73 \pm 2.32$ & $4.00 \pm 2.36$ & $0.01 \pm 0.05$ & $0.09 \pm 0.29$ \\
\hline & $\operatorname{NME}(\%)$ & 4.4 & 41.1 & 63.1 & 30.3 & - & 13.0 \\
\hline & NMB (\%) & -3.3 & 30.4 & -6.8 & 3.3 & - & -13.0 \\
\hline & $\operatorname{MAGE}\left(\mu \mathrm{g} \mathrm{m}^{-3}\right)$ & 0.75 & 0.75 & 1.17 & 1.17 & - & 0.01 \\
\hline & $\operatorname{MB}\left(\mu \mathrm{g} \mathrm{m}^{-3}\right)$ & -0.56 & 0.56 & -0.13 & 0.13 & - & -0.01 \\
\hline & $\operatorname{RMSE}\left(\mu \mathrm{g} \mathrm{m}^{-3}\right)$ & 0.91 & 0.91 & 1.38 & 1.38 & 0.05 & 0.03 \\
\hline & mean observed $\left(\mu \mathrm{g} \mathrm{m}^{-3}\right)$ & $16.63 \pm 8.27$ & $2.54 \pm 1.71$ & 0.00 & $7.31 \pm 4.89$ & - & $0.28 \pm 0.33$ \\
\hline \multirow{7}{*}{$\begin{array}{l}\mathrm{CF}=2 \\
\text { (14 data) }\end{array}$} & mean predicted $\left(\mu \mathrm{g} \mathrm{m}^{-3}\right)$ & $16.25 \pm 8.09$ & $2.92 \pm 1.83$ & $0.98 \pm 1.14$ & $6.32 \pm 5.30$ & $0.06 \pm 0.17$ & $0.24 \pm 0.30$ \\
\hline & $\operatorname{NME}(\%)$ & 3.0 & 19.4 & - & 13.5 & - & 23.9 \\
\hline & NMB (\%) & -2.3 & 15.0 & - & -13.5 & - & -23.9 \\
\hline & $\operatorname{MAGE}\left(\mu \mathrm{g} \mathrm{m}^{-3}\right)$ & 0.49 & 0.49 & 0.98 & 0.98 & - & 0.07 \\
\hline & $\operatorname{MB}\left(\mu \mathrm{g} \mathrm{m}^{-3}\right)$ & -0.38 & 0.38 & 0.98 & -0.98 & - & -0.07 \\
\hline & $\operatorname{RMSE}\left(\mu \mathrm{g} \mathrm{m}^{-3}\right)$ & 0.68 & 0.68 & 1.47 & 1.47 & 0.18 & 0.09 \\
\hline & mean observed $\left(\mu \mathrm{g} \mathrm{m}^{-3}\right)$ & $22.47 \pm 15.43$ & $2.27 \pm 1.41$ & 0.00 & $5.70 \pm 4.05$ & - & $0.48 \pm 1.06$ \\
\hline \multirow{6}{*}{$\begin{array}{l}\mathrm{CF}=3 \\
\text { (11 data) }\end{array}$} & mean predicted $\left(\mu \mathrm{g} \mathrm{m}^{-3}\right)$ & $21.99 \pm 15.16$ & $2.74 \pm 1.64$ & $0.73 \pm 1.05$ & $4.96 \pm 4.03$ & $0.02 \pm 0.06$ & $0.46 \pm 1.05$ \\
\hline & $\operatorname{NME}(\%)$ & 2.3 & 23.2 & - & 12.9 & - & 5.8 \\
\hline & NMB (\%) & -2.1 & 21.0 & - & -12.9 & - & -5.8 \\
\hline & $\operatorname{MAGE}\left(\mu \mathrm{g} \mathrm{m}^{-3}\right)$ & 0.53 & 0.53 & 0.73 & 0.73 & - & 0.03 \\
\hline & $\operatorname{MB}\left(\mu \mathrm{g} \mathrm{m}^{-3}\right)$ & -0.48 & 0.48 & 0.73 & -0.73 & - & -0.03 \\
\hline & $\operatorname{RMSE}\left(\mu \mathrm{g} \mathrm{m}^{-3}\right)$ & 0.64 & 0.64 & 1.24 & 1.24 & - & 0.01 \\
\hline
\end{tabular}

respectively in $\mu \mathrm{g} \mathrm{m}^{-3}$, while NME and NMB in \%; RMSE is the root of the mean square error, which, being the second moment of the error, incorporates both the variance of the prediction and its bias (in $\mu \mathrm{g} \mathrm{m}^{-3}$ ). Both NME and MAGE inherently include the bias which is the reason why the magnitude of NME (and MAGE) is equal or larger than NMB (and MB respectively). For an unbiased prediction, NME and MAGE express the variance. When NME and NMB (or MAGE and MB respectively) are close to each other in magnitude, the discrepancy is explained as a systematic bias rather than scatter. When the magnitude of NME/MAGE is much larger than NMB/MB, part of the discrepancy between predictions and observations is explained as scatter.
Very good agreement between model predictions and observations was found for $\mathrm{NH}_{3(\mathrm{~g})}$ (Fig. 2a) with a NME of $5.3 \%$, a slope of 0.991 , an intercept of $-0.676 \mu \mathrm{g} \mathrm{m}^{-3}$ (much smaller than concentrations of $\left.\mathrm{NH}_{3(\mathrm{~g})}\right)$ and an $R^{2}$ of 0.992 . When compared to the observed value $\left(16.89 \mu \mathrm{g} \mathrm{m}^{-3}\right)$, the mean error and bias, as well as the RMSE for $\mathrm{NH}_{3(\mathrm{~g})}$ are notably low (0.94, -0.83 and $1.27 \mu \mathrm{g} \mathrm{m}^{-3}$ respectively). This is not surprising, as most of the ammonia resides in the gas phase, so $\mathrm{NH}_{3(\mathrm{~g})}$ is relatively insensitive to aerosol ammonium prediction errors. Particulate ammonium (Fig. 2b) was systematically overpredicted, as shown by the $37.1 \%$ NMB and the $0.83 \mu \mathrm{g} \mathrm{m}^{-3}$ mean bias compared to the measured value of $2.24 \mu \mathrm{g} \mathrm{m}^{-3}$ (Table 1). This overprediction could 

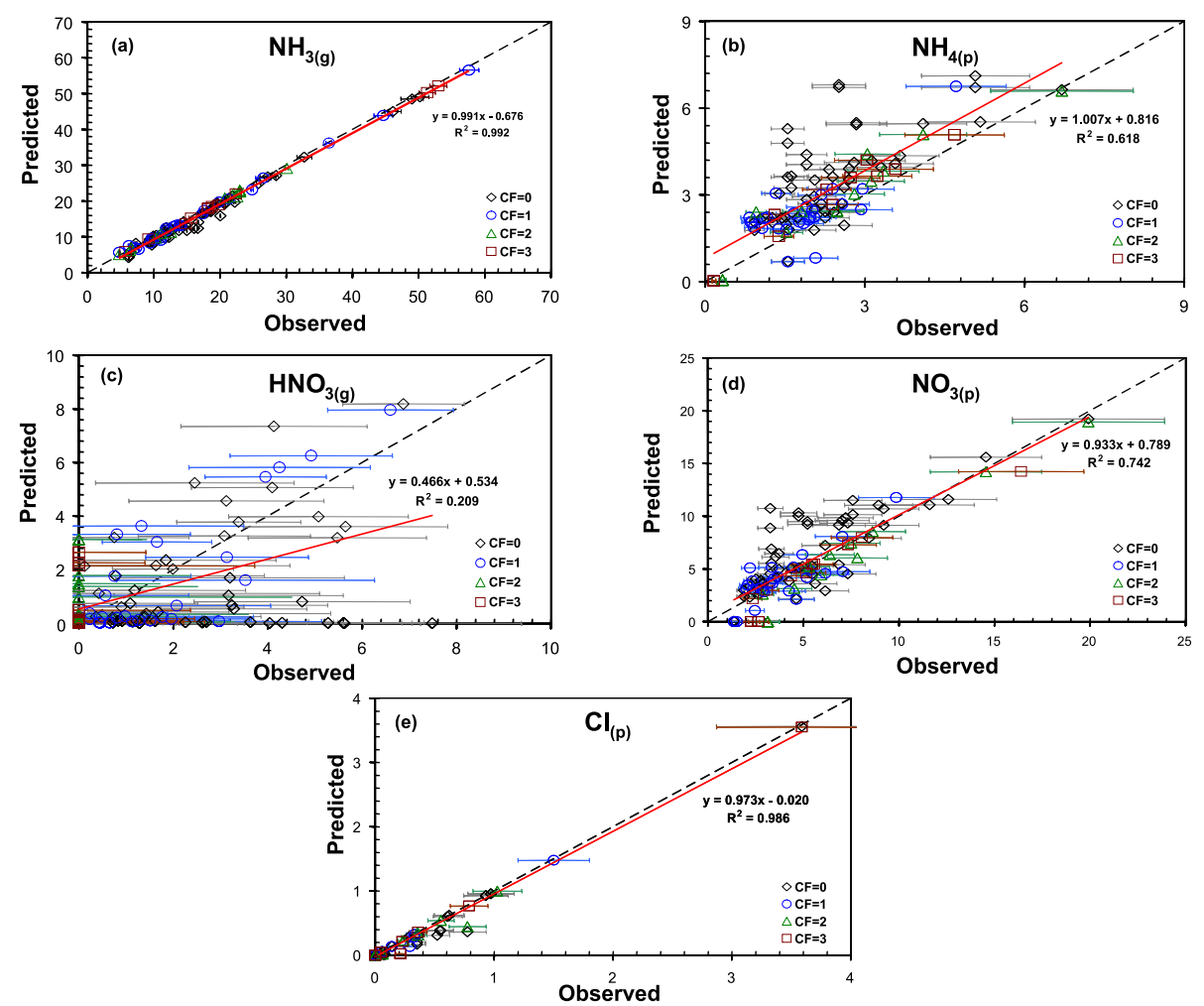

Fig. 2. Predicted versus observed concentrations $\left(\mu \mathrm{g} \mathrm{m}^{-3}\right.$ ) of (a) $\mathrm{NH}_{3(\mathrm{~g})}$, (b) $\mathrm{NH}_{4(p)}$, (c) $\mathrm{HNO}_{3(\mathrm{~g})}$, (d) $\mathrm{NO}_{3(p)}$, and (e) $\mathrm{Cl}_{(p)}$ during the MILAGRO 2006 campaign. Description of legend is given in text. Linear regression line (for all data) is shown for reference. ISORROPIA-II was run assuming stable state solution.

arise from the phase state assumption, departure from equilibrium or measurement uncertainty; all of these possibilities are explored in the subsequent sections.

Predictions of $\mathrm{HNO}_{3(\mathrm{~g})}$ were subject to significant scatter (Fig. 2c), with a NME of $80.8 \%$ and MAGE $=1.46 \mu \mathrm{g} \mathrm{m}^{-3}$ but the bias was comparable to the other species (Table 1). The scatter is attributed to that $a$ ) particles larger than $2.5 \mu \mathrm{m}$ in diameter are not included in our calculations (although too large to be in equilibrium with the gas phase, they could still react with nitric acid and introduce some prediction error), $b$ ) zero concentrations of $\mathrm{HNO}_{3(\mathrm{~g})}$ for a portion of the data $(\mathrm{CF}=2$ and 3$)$, and, $c)$ low, on average, concentrations of gas phase nitrate which results in predictions of $\mathrm{HNO}_{3}(\mathrm{~g})$ being very sensitive to errors in particulate nitrate $\left(\mathrm{NO}_{3(p)}\right)$. When partitioning is predominantly in one phase, small errors in its predicted concentration are substantially amplified in the other phase. Additionally, the estimated uncertainty for $\mathrm{HNO}_{3(\mathrm{~g})}$ (using Eq. 1) was found to be roughly 100\%; the agreement between predicted and observed $\mathrm{HNO}_{3(\mathrm{~g})}$ is in fact within the estimated uncertainty. For particulate nitrate (Fig. 2d), ISORROPIA-II predictions agree well with observations with a NME of $27.2 \%$ and a small bias $(\mathrm{NMB}=8.0 \%)$.

Observed concentrations of $\mathrm{Cl}^{-}$agree well (NME $=15.5 \%$, MAGE $=0.04 \mu \mathrm{g} \mathrm{m}^{-3}$ ) with predicted values (Fig. 2e); ISORROPIA-II predicts very small amounts of chloride in the gas phase because the large excess of $\mathrm{NH}_{3(\mathrm{~g})}$ tends to drive $\mathrm{Cl}^{-}$almost completely into the aerosol phase. This justifies (to first order) the assumption of effectively zero $\mathrm{HCl}_{(g)}$ in the thermodynamic calculations. However, the NME and $\mathrm{NMB}$, as well as MAGE and MB, are almost identical in magnitude; this suggests that the prediction error is likely only from the "missing" (small) amount of $\mathrm{HCl}_{(g)}$ that are not considered in the calculations of Fig. 2e. Minimizing the NMB would require on average $0.03 \mu \mathrm{g} \mathrm{m}^{-3}$ gas-phase $\mathrm{HCl}$ (min: 0, max: $0.3 \mu \mathrm{g} \mathrm{m}^{-3}$ ), which is consistent with the sub-ppb estimates of $\mathrm{HCl}_{(g)}$ by San Martini et al. (2006) for Mexico City aerosol during MCMA-2003 and with measurements ( $\sim 1 \mathrm{ppb}$ ) reported by Moya et al. (2004).

Although NMB strongly depends on the averaging time, NME does not (the same is seen for MB and MAGE, respectively). This may be the residual effect of particles with diameter larger than $2.5 \mu \mathrm{m}$ reacting with nitrates; since coarse particles vary significantly throughout the dataset and are not included in our calculations, their effect likely manifests as "scatter" in the predictions. This suggests that up to $1.46 \mu \mathrm{g} \mathrm{m}^{-3}$ (MAGE value for nitrate) out of the $5.38 \mu \mathrm{g} \mathrm{m}^{-3}$ observed, which is roughly $30 \%$ of the unresolved particulate nitrate (also expressed as $\sim 30 \% \mathrm{NME}$ ) could be associated with particles larger than $2.5 \mu \mathrm{m}$ diameter. 


\subsection{Equilibrium timescale}

Agreement between predictions and measurements depends on many factors, such as equilibrium timescale and measurement uncertainty. Figure 2 (and Table 1) shows that the closure for $\mathrm{CF}=0$ data is slightly worse than for $\mathrm{CF}=1$ to 3 , which could be an indication that the averaging timescale might affect the bias. Since the NMB and NME for particulate nitrate are consistent between CF classifications, this suggests that the TD-LIF provides an excellent measure of volatile nitrate. Based on work to date (e.g., Meng and Seinfeld, 1996; Dassios and Pandis, 1999; Cruz et al., 2000) we expect the equilibration timescale to be $\sim 20 \mathrm{~min}$; indeed the Table 1 results support this, as NMB is consistently minimum for the 20 min data (Table 1). However, since different data correspond to different atmospheric conditions (temperature, relative humidity, time), no definite conclusion on the equilibration timescale can be drawn based on the error metrics. An equilibrium timescale and its sensitivity to changes in RH, $T$ and aerosol precursor concentration can still be derived from the measurements. For this, we start from the mass transport equation from/to particle:

$$
\frac{d m}{d t}=k\left(c-c_{e q}\right)
$$

where $k$ is the mass transfer coefficient, $c$ is the ambient concentration of a species and $c_{e q}$ is its concentration at equilibrium. $k$ depends on the gas-phase diffusivity, the size of the particle and the mass accommodation coefficient (Seinfeld and Pandis, 1998), $k=\left(\frac{R_{p}^{2}}{3 D_{g}}+\frac{R_{p}}{3 a} \sqrt{\frac{2 \pi M_{A}}{R T}}\right)^{-1}$ where $R_{p}$ is the effective radius of the particle, $D_{g}$, the gas-phase diffusivity and $a$ the mass accommodation coefficient. For values of $\alpha>0.1$, the mass transfer rate is not sensitive to the exact value of $\alpha$ (Seinfeld and Pandis, 2006) and thus the above equation can be simplified:

$k=\frac{3 D_{g}}{R_{p}^{2}}$

$D_{g}$ was calculated from the Chapman-Enskog theory for binary diffusivity (Seinfeld and Pandis, 2006) and was found to be $0.2 \mathrm{~cm}^{2} \mathrm{~s}^{-1}$ for $\mathrm{NH}_{3}$ and $0.14 \mathrm{~cm}^{2} \mathrm{~s}^{-1}$ for $\mathrm{HNO}_{3}$ (average for the conditions of $T$ and $P$ observed during the measurement period).

Assuming that $c$ changes with time, with a rate, $\frac{d c}{d t}$, obtained from observations, $c=c_{o}+\left(\frac{d c}{d t}\right) t$, where $c_{o}$ is the observed concentration at time $t_{o}$. Substituting into Eq. (2) gives:

$$
\frac{d m}{d t}=k\left\{c_{o}+\left(\frac{d c}{d t}\right) t-c_{e q}\right\}=k\left\{c_{o}-c_{e q}\right\}+k\left(\frac{d c}{d t}\right) t
$$

The characteristic time for equilibrium establishment can be estimated by scaling Eq. (4). If the characteristic aerosol mass concentration is $m_{p}$ and the characteristic timescale is $\tau$ one can scale $t, m$ as $t^{\prime}=\frac{t}{\tau}$ and $m^{\prime}=\frac{m}{m_{p}}$, respectively. Substitution into Eq. (4) gives,

$$
\frac{m_{p}}{\tau} \frac{d m^{\prime}}{d t^{\prime}}=k\left\{c_{o}-c_{e q}\right\}+k\left(\frac{d c}{d t}\right) t^{\prime} \tau
$$

Equation (5) can be rewritten as $\frac{m_{p}}{k(d c / d t) \tau^{2}} \frac{d m^{\prime}}{d t^{\prime}}=$ $\frac{1}{(d c / d t) \tau}\left\{c_{o}-c_{e q}\right\}+t^{\prime}$. If the particle is close to equilibrium at time $t_{o}$ (which largely applies here), $c_{o} \sim c_{e q}$ and the first term on the right hand side of Eq. (5) can be neglected. Since the two remaining terms balance each other, they are of the same magnitude, hence the characteristic equilibrium timescale can be defined as,

$$
\tau=\left(\frac{m_{p}}{k \Delta c / \Delta t}\right)^{1 / 2}
$$

where $\Delta c, \Delta t$ are the changes in concentration and time (in units of $\mu \mathrm{g} \mathrm{m}^{-3}$ and s) respectively, between two consecutive measurements. $k$ is the mass transfer coefficient in $\mathrm{s}^{-1}$ and $m_{p}$ is the characteristic mass concentration in $\mu \mathrm{g} \mathrm{m}^{-3}$.

Assuming a particle density of $1.0 \mathrm{~g} \mathrm{~cm}^{-3}$ (characteristic for deliquesced aerosol exposed to high $\mathrm{RH}$ ) a mass accommodation coefficient of 0.1 for gas-phase $\mathrm{NH}_{3}, \mathrm{HNO}_{3}$ and an aerosol diameter of $1 \mu \mathrm{m}$, the timescale for equilibrium for all semivolatile species is computed using Eq. (6), and shown in Fig 3. Semivolatile partitioning equilibrates (on average) on a timescale between 15-30 min (Fig. 3a, b) during the measurement period of 21-30 March $(27 \pm 19 \mathrm{~min}$ for $\mathrm{HNO}_{3}, 14 \pm 11 \mathrm{~min}$ for $\mathrm{NH}_{3}, 18 \pm 15 \mathrm{~min}$ for $\mathrm{NO}_{3}$ and $15 \pm 13$ min for $\mathrm{NH}_{4}$, on average). These values are consistent with the detailed calculations of Wexler and Seinfeld (1992), more recent literature (Meng and Seinfeld, 1996; Dassios and Pandis, 1999; Cruz et al., 2000) and the high resolution measurements of nitrate by Hennigan et al. (2008), which shows that measured nitrate lags about $30 \mathrm{~min}$ with respect to predictions based on bulk equilibrium. Furthermore, the equilibration timescale for $\mathrm{NH}_{3}$ is close to that of $\mathrm{NH}_{4}$, and, the timescale of $\mathrm{HNO}_{3}$ is close to that of $\mathrm{NO}_{3}$, despite that they include independent measurements of aerosol and gas-phase precursors; this strongly suggests consistency in the timescale analysis. Interestingly, by focusing on specific days, one can notice a systematic diurnal cycle of the equilibration timescale. Figure $3 \mathrm{c}$ shows the timescale of $\mathrm{NH}_{4}$ and $\mathrm{NO}_{3}$ for two days ( 28 and 29 March). The timescale reaches a maximum during midnight, when $T$ is lower, $\mathrm{RH}$ is high and concentrations of species are high (because of the collapse of the boundary layer). Increasing the particle diameter to $2 \mu \mathrm{m}$ increases the timescales by a factor of 2 , while an increase in aerosol density from 1 to $2 \mathrm{~g} \mathrm{~cm}^{-3}$ increases the equilibration timescale by $\sim 40 \%$ (not shown). 

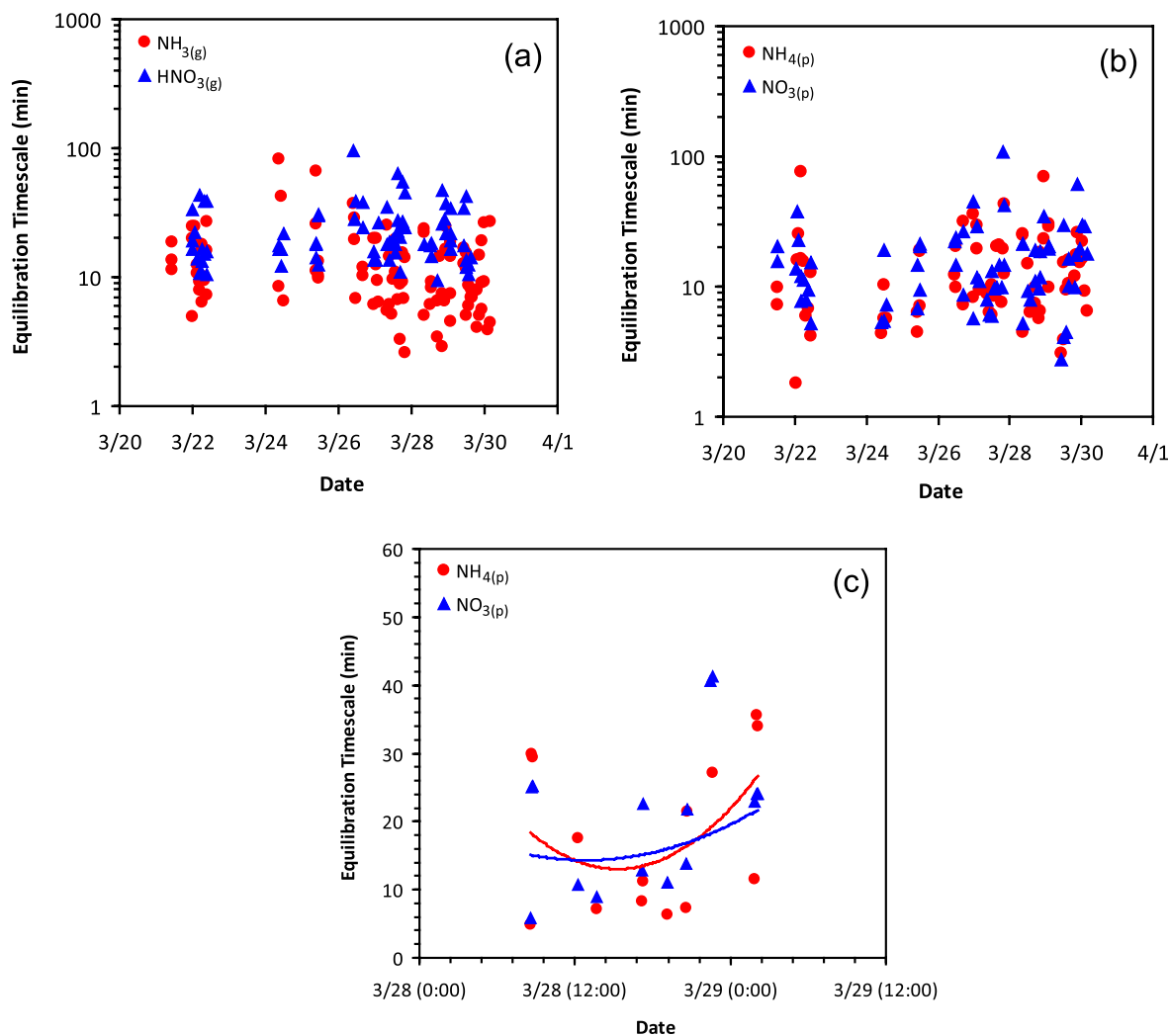

Fig. 3. Equilibration timescales for (a) gas-phase, and (b) semivolatile aerosol species during March 2006. Calculations are done assuming a particle size of $1 \mu \mathrm{m}$. Also shown (c) are timescales for March 28-29 with polynomial temporal trends.

It is also important to evaluate the influence of environmental changes to the equilibration timescale. This is done by evaluating the instantaneous $\tau_{e q}$ (computed from instantaneous values of concentration, $\mathrm{RH}$ and $T$ ) against changes from fluctuations in $c, \mathrm{RH}$ and $T$. The effect of $\left(\frac{d c}{d t}\right)$ is already expressed in Eq. (5); the effects of RH and $T$ are introduced through their effects on equilibrium composition,

$c_{e q}=c_{e q, o}+\frac{\partial C_{e q}}{\partial \mathrm{RH}} d \mathrm{RH}+\frac{\partial C_{e q}}{\partial T} d T$

Introduction of Eq. (7) into Eq. (4) gives:

$$
\begin{gathered}
\quad \frac{d m}{d t}=k\left\{c_{o}-\left(c_{e q, o}+\frac{\partial C_{e q}}{\partial \mathrm{RH}} d \mathrm{RH}+\frac{\partial C_{e q}}{\partial T} d T\right)\right\}+k\left(\frac{d c}{d t}\right) t \\
=k\left(c_{o}-c_{e q, o}\right)-k\left(\frac{\partial C_{e q}}{\partial \mathrm{RH}} d \mathrm{RH}\right)-k\left(\frac{\partial C_{e q}}{\partial T} d T\right)+k\left(\frac{d c}{d t}\right) t
\end{gathered}
$$

The terms on the right hand side of Eq. (8) express (from left to right) the rate of change of particle mass from the instantaneous departure of concentration from equilibrium, the effect of RH change, $T$ change, and, aerosol precursor change. The latter 3 are affected by changes in environmental conditions, and the first term is associated with the instantaneous equilibration timescale, $\tau_{e q}$. Because of this, one can define the ratio of $\tau_{e q}$ to the timescale of $\mathrm{RH}$ variations, $\tau_{\mathrm{RH}}$, as:

$$
\frac{\tau_{e q}}{\tau_{\mathrm{RH}}}=\left(\frac{\frac{\partial C_{e q}}{\partial \mathrm{RH}} d \mathrm{RH}}{\left(c_{o}-c_{e q, o}\right)}\right) \approx\left(\frac{\frac{\partial C_{e q}}{\partial \mathrm{RH}} \Delta \mathrm{RH}}{\left(c_{o}-c_{e q, o}\right)}\right)
$$

where $\frac{\partial C_{e q}}{\partial \mathrm{RH}}$ is the sensitivity of equilibrium concentration to changes in RH (calculated from ISORROPIA-II, by evaluating the equilibrium solution at $\mathrm{RH}_{o}$, and, $\mathrm{RH}_{o}+0.01$ ) and $\Delta \mathrm{RH}$ is the observed change in $\mathrm{RH}$ between two consecutive measurements. Similarly, one can define the ratio of timescales of instantaneous equilibration to $T$ variations, $\tau_{T}$ as:

$\frac{\tau_{e q}}{\tau_{T}}=\left(\frac{\frac{\partial C_{e q}}{\partial T} d T}{\left(c_{o}-c_{e q, o}\right)}\right) \approx\left(\frac{\frac{\partial C_{e q}}{\partial T} \Delta T}{\left(c_{o}-c_{e q, o}\right)}\right)$

where $\frac{\partial C_{e q}}{\partial T}$ is the sensitivity of equilibrium concentration to changes in $T$ (calculated from ISORROPIA-II, by evaluating the equilibrium solution at $T_{o}$, and, $T_{o}+0.1$ ), and, $\Delta T$ is the observed change in $T$ between two consecutive measurements. 

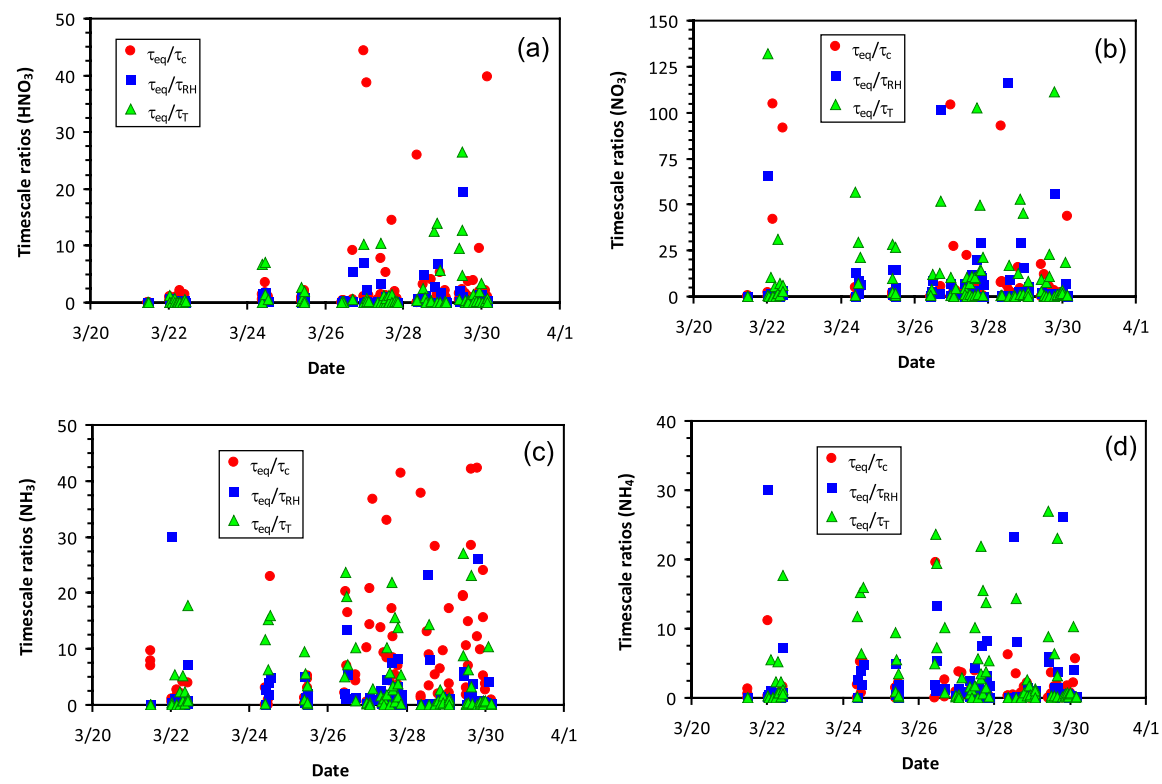

Fig. 4. Timescale ratios for (a) gas-phase $\mathrm{HNO}_{3}$, (b) aerosol $\mathrm{NO}_{3}$, (c) gas-phase $\mathrm{NH}_{3}$, and, (d) aerosol $\mathrm{NH}_{4}$ during the period of 21-30 March 2006.
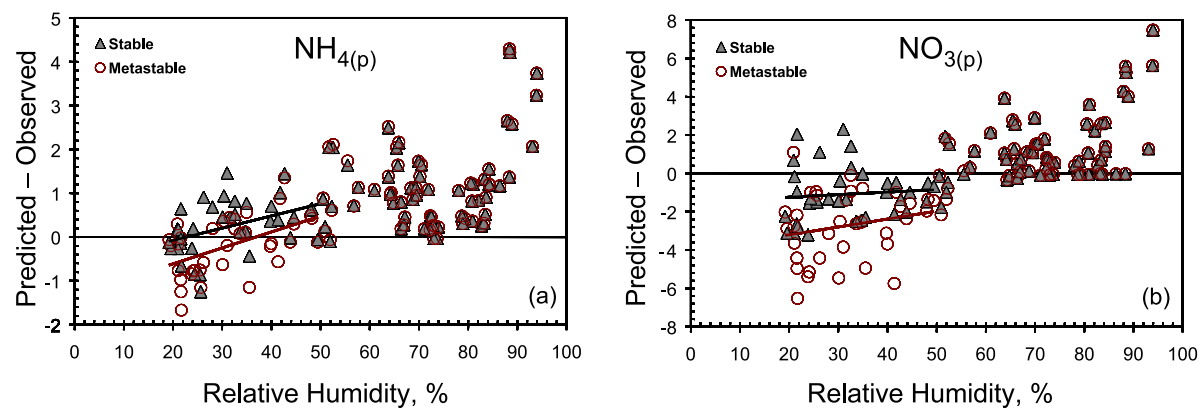

Fig. 5. Difference $\left(\mu \mathrm{g} \mathrm{m}^{-3}\right)$ between predicted and observed concentrations of aerosol (a) ammonium, and, (b) nitrate, as a function of RH using the stable (deliquescence) and metastable solutions of ISORROPIA-II. Linear regression lines are shown for both solutions.

Finally, one can define the ratio of instantaneous equilibration timescale to the rate of change of precursor as:

$\frac{\tau_{e q}}{\tau_{C}}=\left(\frac{\left(\frac{d c}{d t}\right) d t}{\left(c_{o}-c_{e q, o}\right)}\right) \approx\left(\frac{\Delta c}{\left(c_{o}-c_{e q, o}\right)}\right)$

where $\Delta c$ is the change in precursor concentration between two consecutive measurements.

If $\left\{\frac{\tau_{e q}}{\tau_{C}}, \frac{\tau_{e q}}{\tau_{T}}, \frac{\tau_{e q}}{\tau_{\mathrm{RH}}}\right\}<1$, then the equilibrium timescale is dominated by transients in ambient concentration, $\mathrm{RH}, T$ and vice versa. Figure 4 shows the calculated timescale ratios for gas-phase $\mathrm{HNO}_{3}, \mathrm{NH}_{3}$ and aerosol $\mathrm{NO}_{3}, \mathrm{NH}_{4}$ during the measurement period of 21-30 March 2006. If $c$, RH and $T$ change slowly enough, the timescale ratios are much larger than 1 ; this was found to frequently apply in the dataset $(88 \%$ for $\mathrm{NH}_{3}, 58 \%$ for $\mathrm{NH}_{4}, 55 \%$ for $\mathrm{HNO}_{3}$ and $75 \%$ for $\mathrm{NO}_{3}$ ).
This, at first glance, suggests that calculation of the equilibrium timescale based on instantaneous values of $c, \mathrm{RH}, T$ is representative. However, model predictions are never in perfect agreement with observations; the relative contribution of model bias and departure from equilibrium to $c_{o}-c_{e q}$ is therefore unclear. For this reason, Eq. (6) in this study is preferred (i.e., $\tau=\tau_{c}$ ) over $\tau_{e q}$ for representing the aerosol equilibration timescale. This suggests that $\tau_{c}$ is less than $\tau_{\mathrm{RH}}$ or $\tau_{\mathrm{T}}$, meaning that changes in RH and $T$ affect the equilibrium composition over larger timescales (factor of 2 to 10, Fig. 4) than concentration fluctations.

\subsection{Deliquescence vs. metastable state}

Due to the hysteresis effect, there is always an issue on the assumption of thermodynamic state for $\mathrm{RH}<60 \%$, where crystallization may occur (Ansari and Pandis, 2000; Moya et al., 
Table 2. Prediction skill metrics of ISORROPIA-II, for stable and metastable solutions. Data is shown for RH $<50 \%$.

\begin{tabular}{llllll}
\hline Aerosol state & Metric & $\mathrm{NH}_{3(\mathrm{~g})}$ & $\mathrm{NH}_{4(p)}$ & $\mathrm{HNO}_{3(\mathrm{~g})}$ & $\mathrm{NO}_{3(p)}$ \\
\hline \multirow{3}{*}{ Stable } & NME $(\%)$ & 3.6 & 24.3 & 67.7 & 25.8 \\
$(37$ data) & NMB $(\%)$ & -1.6 & 11.0 & 48.5 & -18.5 \\
& MAGE $\left(\mu \mathrm{g} \mathrm{m}^{-3}\right)$ & 0.5 & 0.5 & 1.5 & 1.5 \\
& $\mathrm{MB}\left(\mu \mathrm{g} \mathrm{m}^{-3}\right)$ & -0.2 & 0.2 & 1.1 & -1.1 \\
Metastable & $\mathrm{NME}(\%)$ & 3.6 & 24.3 & 124.3 & 47.4 \\
$(37$ data $)$ & NMB $(\%)$ & 1.3 & -9.0 & 121.6 & -46.4 \\
& MAGE $\left(\mu \mathrm{g} \mathrm{m}^{-3}\right)$ & 0.50 & 0.50 & 2.80 & 2.80 \\
& MB $\left(\mu \mathrm{g} \mathrm{m}^{-3}\right)$ & 0.20 & -0.20 & 2.74 & -2.74 \\
\hline
\end{tabular}

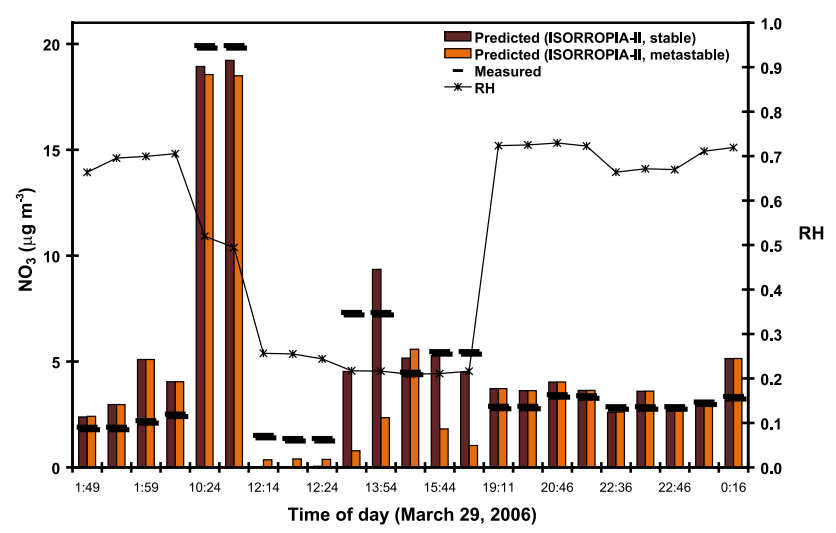

Fig. 6. Diurnal profile of aerosol nitrate and RH for March 29, 2006.

2002). This dataset covers a wide range of RH (19-94\%) and makes it possible to assess the preferred phase transition path (i.e. deliquescence or metastable branch) for Mexico City aerosol. In Fig. 5 we plot the stable ("deliquescence") and metastable ("metastable") solution predictions of ISORROPIA-II compared to observations for $\mathrm{NH}_{4(p)}$ and $\mathrm{NO}_{3(p)}$ as a function of $\mathrm{RH}$ for the whole dataset (21-30 March). The stable state solution of ISORROPIA-II predicts higher concentrations of aerosol ammonium and aerosol nitrate at $\mathrm{RH}<50 \%$. This is in agreement with previous studies (Ansari and Pandis, 2000) and is primarily attributed to high concentrations of ammonium nitrate formed in the stable state solution of ISORROPIA-II through the reaction $\mathrm{NH}_{3(\mathrm{~g})}+\mathrm{HNO}_{3(\mathrm{~g})} \leftrightarrow \mathrm{NH}_{4} \mathrm{NO}_{3(\mathrm{~s})}$. At low $\mathrm{RH}(<50 \%)$, the stable state solution predicts a solid phase consisting mainly of $\left(\mathrm{NH}_{4}\right)_{2} \mathrm{SO}_{4}$ and $\mathrm{NH}_{4} \mathrm{NO}_{3}$. The metastable state solution assumes the particulates are composed of an aqueous supersaturated solution throughout the whole $\mathrm{RH}$ regime; hence no solid $\mathrm{NH}_{4} \mathrm{NO}_{3}$ is allowed to form. At $\mathrm{RH}>50 \%$, solid $\mathrm{NH}_{4} \mathrm{NO}_{3}$ dissolves and "stable" and "metastable" aerosol predictions become identical. This can also be seen in Fig. 6, which presents the observed and predicted (by both solutions of ISORROPIA-II) aerosol nitrate diurnal profile for 29 March. During the early morning and night, when RH is high, both solutions predict the same concentration. For periods of high RH, the model slightly overpredicts the measured particulate nitrate concentrations, while at low RH $(<30 \%)$ it generally underpredicts. Possible reasons for this could be the presence of WSOC influencing the partitioning of inorganic species between the gas and aerosol phase (not considered by ISORROPIA-II); the existence of other species (not modeled) by ISORROPIA-II would lower the mutual deliquescence point and increase the amount of dissolved nitrate in the aerosol phase at low RH.

The differences between stable and metastable solutions predictions shown in Fig. 5 are quantified in Table 2; NME, NMB, MAGE and MB are computed only for data with $\mathrm{RH}<50 \%$. For aerosol ammonium, although the NME (and MAGE) for the two solutions of ISORROPIA-II is essentially the same, the opposite sign in NMB and MB (Table 2 ), indicates an overprediction $(+11 \%)$ of ammonium by the stable state and an underprediction $(-9 \%)$ by the metastable solution. The systematic overprediction of ammonium by the stable solution (seen in Fig. 2) may partially reflect measurement uncertainty, which is analyzed in detail in Sect. 4.4. For aerosol nitrate, the error and bias between predictions and observations is significantly larger when using the metastable solution (NME $=47.4 \%, \mathrm{NMB}=-46.4 \%$, MAGE $\left.=2.8 \mu \mathrm{g} \mathrm{m}^{-3}, \mathrm{MB}=-2.74 \mu \mathrm{g} \mathrm{m}^{-3}\right)$ of ISORROPIAII compared to the stable state solution (NME $=25.8 \%$, $\mathrm{NMB}=-18.5 \%$, MAGE $=1.5 \mu \mathrm{g} \mathrm{m}^{-3}, \mathrm{MB}=-1.1 \mu \mathrm{g} \mathrm{m}^{-3}$ ) for $\mathrm{RH}<50 \%$, suggesting that aerosols in Mexico City prefer the deliquescence branch of the phase diagram. However, Moya et al. (2007) showed that the metastable branch predictions gives better agreement with observations at low RH during the MER 2005 campaign (Mexico City downtown). An important difference between the two datasets is the sulfate-to-nitrate $\left(\mathrm{SO}_{4}^{2-} / \mathrm{NO}_{3}^{-}\right)$molar ratio, being larger than unity for the MER data and less than unity for the current dataset (on average $\mathrm{SO}_{4}^{2-} / \mathrm{NO}_{3}^{-} \approx 0.7$ ). Since a subset of the current dataset exhibited a $\mathrm{SO}_{4}^{2-} / \mathrm{NO}_{3}^{-}$larger than 1 , we examine the possibility that particulate $\mathrm{SO}_{4}^{2-} / \mathrm{NO}_{3}^{-}$correlates with a change in the preferred phase state for $\mathrm{RH}$ below 50\%. In Table 3 we show the performance of both 
stable and metastable solution of ISORROPIA-II at RH below $50 \%$ and for aerosol $\mathrm{SO}_{4}^{2-} / \mathrm{NO}_{3}^{-}$ratio larger and less than 1 . At aerosol $\mathrm{SO}_{4}^{2-} / \mathrm{NO}_{3}^{-}<1, \mathrm{NME}$ and $\mathrm{NMB}$ are much larger in the metastable solution for $\mathrm{HNO}_{3(\mathrm{~g})}$ and $\mathrm{NO}_{3(p)}$ and slightly larger for $\mathrm{NH}_{3(\mathrm{~g})}$ and $\mathrm{NH}_{4(p)}$ while for aerosol $\mathrm{SO}_{4}^{2-} / \mathrm{NO}_{3}^{-}>1$ the opposite is seen (although with much smaller differences in NMB between the two solutions). The results of this study, combined with Moya et al. (2007) suggest that the stable state is preferred when $\mathrm{SO}_{4}^{2-} / \mathrm{NO}_{3}^{-}<1$ and vice versa. However, this serves only as an indication, as there is relatively few data (12 points) for which $\mathrm{SO}_{4}^{2-} / \mathrm{NO}_{3}^{-}>1$ at $\mathrm{RH}<50 \%$. More data are needed to further substantiate this hypothesis.

The existence of metastable aerosol for low RH may seem at first surprising, particularly since crustal species, which tend to promote efflorescence under supersaturated conditions, are present (e.g., Martin et al. (2001) reported that efflorescence is rapid for deliquesced $\left(\mathrm{NH}_{4}\right)_{2} \mathrm{SO}_{4}$ aerosol at $35 \% \mathrm{RH})$. If substantial amounts of predicted solid $\mathrm{CaSO}_{4}$ is used as a proxy for crustal influence, only $25 \%$ of the points for which $\mathrm{SO}_{4} / \mathrm{NO}_{3}>1$ are influenced; $48 \%$ of the data are influenced when $\mathrm{SO}_{4} / \mathrm{NO}_{3}<1$. This suggests that crustals may indeed influence the phase state of aerosol, although organic compounds (not considered by ISORROPIA-II) can form eutectic mixtures that contain thermodynamically stable water down to very low RH, thus giving the "appearance" of a metastable state (Marcolli et al., 2004). Unfortunately, measurements of particle phase state or size-resolved compositional data were not available with the time resolution required to support our results, although the model suggests the semi-volatile inorganic partitioning is mostly consistent with a metastable state whenever dust is not present in significant amounts.

ISORROPIA-II (and most other thermodynamic aerosol models as well) make use of the water activity-molality polynomials for inorganic salts developed by fitting electrodynamic balance measurements at $>30 \% \mathrm{RH}$ (Fountoukis and Nenes, 2007). Inaccuracies in water content associated with extrapolation of the water activity polynomials could bias the "favored" state in the low-RH samples. Fortunately, most of the datapoints in our study are for an ambient $\mathrm{RH}$ above $30 \%$. Repeating the exercise neglecting datapoints for which $\mathrm{RH}<30 \%$ yielded no discernable difference in the performance metrics (not shown).

Another important issue arising from the data depicted in Fig. 6 is the large variations in RH, $T$ and species concentrations during different times of the day, and the implications thereof. During morning (10:00 a.m.-12:00 noon) and evening hours (03:30 p.m.-07:30 p.m.), large changes in RH occur which prevent the use of low temporal resolution measurements (even if size-resolved, for aerosol species), as they substantially deviate (sometimes by more than $100 \%$ ) from the 5-min measurements. For example, the average RH measured between 04:00 p.m. and 07:00 p.m. on 29th March was
$56 \%$ but varied between $22 \%$ and $73 \%$ over the same period. Similar \% changes are seen for the measured temperature. Even for nighttime and afternoon periods (when RH and $T$ do not vary significantly) (Fig. 6), large changes are observed in the semivolatile species concentrations. For instance, average $\mathrm{NH}_{3(\mathrm{~g})}$ concentration measured between 08:00 p.m. and 11:00 p.m. on 29th March was 17.2 $\mu \mathrm{g} \mathrm{m}^{-3}$, while at 10:30 p.m., this value was $10.9 \mu \mathrm{g} \mathrm{m}^{-3}$ (57\% difference). For the same time period, the $\%$ variability in $\mathrm{NH}_{4(p)}$, $\mathrm{HNO}_{3(\mathrm{~g})}$ and $\mathrm{NO}_{3(p)}$ was found to be up to $18 \%, 100 \%$, and $20 \%$, respectively. The large temporal variability in $\mathrm{RH}$, $T$, gas- and aerosol-phase species showcases the importance of high-resolution temporal measurements; this also implies that application of an equilibrium model to measurements (bulk or size-resolved) with long integration times is questionable.

4.4 Sensitivity of model predictions to aerosol precursor concentrations

In this section we explore the sensitivity of predictions to aerosol precursor concentrations to a) assess the importance of measurement uncertainty on predictions, and, b) assess the sensitivity of $\mathrm{PM}_{2.5}$ to changes in emitted precursors. The sensitivity is assessed by perturbing the input concentrations of total ammonia (TA), total nitrate (TN), total sulfate (TS), crustals and sodium by $\pm 20 \%$ (approximately the PILS measurement uncertainty). The results of this analysis are shown in Table 4. A $20 \%$ increase in TS does not improve the agreement between predictions and observations; in fact, a slight increase of the NME was found for ammonia and nitrate. Since the impactor data showed $\sim 40 \%$ (on average) higher TS than the PILS (not shown), we further perturb TS by $40 \%$, but NME does not decrease $\left(67.9 \%\right.$ for $\mathrm{NH}_{4(p)}$ and $27.8 \%$ for $\left.\mathrm{NO}_{3(p)}\right)$. A $+20 \%$ perturbation in crustals and sodium concentrations however, slightly improved predictions of $\mathrm{NH}_{3(\mathrm{~g})}$ and $\mathrm{NH}_{4(p)}$ and decreased the observed overprediction seen in Fig. 2b; this is because crustals and sodium preferentially neutralize sulfates, so less ammonia binds to form $\left(\mathrm{NH}_{4}\right)_{2} \mathrm{SO}_{4}$ which decreases the predicted $\mathrm{NH}_{4(p)}$ concentration and increases the amount of $\mathrm{NH}_{3(\mathrm{~g})}$. In fact, the impactor data suggest that $\mathrm{Ca}^{2+}, \mathrm{Mg}^{2+}$ and $\mathrm{Na}^{2+}$ are much higher (approximately 4 times) than obtained with the PILS. Increasing crustals and sodium by a factor of 4 significantly decreases the systematic error between predictions and measurements for particulate ammonium $(\mathrm{NMB}=13.6 \%)$; predictions for $\mathrm{NH}_{3(\mathrm{~g})}$ (mean predicted value $=17.42 \mu \mathrm{g} \mathrm{m}^{-3}$ ) and $\mathrm{NH}_{4(p)}$ (mean predicted value $=2.55 \mu \mathrm{g} \mathrm{m}^{-3}$ ) are improved. This implies that the PILS in this dataset may not account for all the crustals present in $\mathrm{PM}_{2.5}$.

In Fig. 7 we plot the predicted change (\%) in $\mathrm{PM}_{2.5}$ nitrate as a function of RH when a $20 \%$ decrease in input concentrations of TA, TS and TN is applied. The nitrate response to sulfate is negligible, $\Delta x=0.36 \%$, (Fig. 7 , Table 4) because TA 
Table 3. Prediction skill metrics of ISORROPIA-II, for stable and metastable solutions. Data is shown for RH<50\% and for sulfate-to-nitrate molar ratio larger and less than unity.

\begin{tabular}{|c|c|c|c|c|c|}
\hline Solution Type & Error Metric & $\mathrm{NH}_{3(\mathrm{~g})}$ & $\mathrm{NH}_{4}(p)$ & $\mathrm{HNO}_{3(\mathrm{~g})}$ & $\mathrm{NO}_{3}(p)$ \\
\hline & \multicolumn{5}{|c|}{$\mathrm{SO}_{4} / \mathrm{NO}_{3}>1$} \\
\hline Stable & $\operatorname{NME}(\%)$ & 4.9 & 38.7 & 28.8 & 41.5 \\
\hline \multirow[t]{3}{*}{ (12 data) } & NMB (\%) & 0.6 & -4.7 & 24.9 & -35.8 \\
\hline & $\operatorname{MAGE}\left(\mu \mathrm{g} \mathrm{m}^{-3}\right)$ & 0.76 & 0.76 & 0.89 & 0.89 \\
\hline & $\mathrm{MB}\left(\mu \mathrm{g} \mathrm{m}^{-3}\right)$ & 0.09 & -0.09 & 0.76 & -0.76 \\
\hline Metastable & NME (\%) & 4.4 & 35.2 & 27.0 & 38.8 \\
\hline \multirow[t]{4}{*}{ (12 data) } & $\mathrm{NMB}(\%)$ & 0.5 & -3.9 & 23.0 & -33.1 \\
\hline & $\operatorname{MAGE}\left(\mu \mathrm{g} \mathrm{m}^{-3}\right)$ & 0.69 & 0.69 & 0.83 & 0.83 \\
\hline & $\operatorname{MB}\left(\mu \mathrm{g} \mathrm{m}^{-3}\right)$ & 0.08 & -0.08 & 0.71 & -0.71 \\
\hline & \multicolumn{5}{|c|}{$\mathrm{SO}_{4} / \mathrm{NO}_{3}<1$} \\
\hline Stable & NME $(\%)$ & 3.0 & 21.2 & 82.1 & 24.3 \\
\hline \multirow[t]{3}{*}{ (25 data) } & NMB (\%) & -2.1 & 14.7 & 56.2 & -16.6 \\
\hline & $\operatorname{MAGE}\left(\mu \mathrm{g} \mathrm{m}^{-3}\right)$ & 0.49 & 0.49 & 1.59 & 1.59 \\
\hline & $\operatorname{MB}\left(\mu \mathrm{g} \mathrm{m}^{-3}\right)$ & -0.34 & 0.34 & 1.09 & -1.09 \\
\hline Metastable & NME (\%) & 3.1 & 21.8 & 159.0 & 47.0 \\
\hline \multirow[t]{3}{*}{ (25 data) } & NMB (\%) & 1.1 & -7.7 & 155.4 & -46.0 \\
\hline & $\operatorname{MAGE}\left(\mu \mathrm{g} \mathrm{m}^{-3}\right)$ & 0.50 & 0.50 & 3.09 & 3.09 \\
\hline & $\mathrm{MB}\left(\mu \mathrm{g} \mathrm{m}^{-3}\right)$ & 0.18 & -0.18 & 3.02 & -3.02 \\
\hline
\end{tabular}

concentrations are substantially in excess, and, thus a $20 \%$ change in and TS is insufficient to affect the formation of ammonium nitrate. (In an ammonia-limited environment, a reduction in sulfate would increase aerosol nitrate as ammonia is freed and allowed to react with nitric acid). As seen in Fig. 7, nitrate predictions are sensitive to changes in TA only for $\mathrm{RH}<60 \%$. This is expected since below the deliquescence point of $\mathrm{NH}_{4} \mathrm{NO}_{3}$ the partitioning of nitrate is strongly dependent on the ammonia vapor pressure and thus reducing TA reduces the amount of $\mathrm{NH}_{4} \mathrm{NO}_{3}$ formed. At $\mathrm{RH}>60 \%$, nitrate is mostly dissolved and unaffected by the changes in TA. Aerosol nitrate predictions are more directly influenced by reductions in TN as shown in Fig. 7 and Table $4(\Delta x=-$ $22.8 \%$ ), and is in agreement with Takahama et al. (2004). The sensitivity of aerosol nitrate is RH-dependent as the partitioning of nitrate strongly depends on the amount of aerosol water.

\subsection{Importance of explicitly treating crustal species}

Often thermodynamic models treat the presence of crustals as mole-equivalent sodium (i.e. $\mathrm{Ca}^{2+}=2 \mathrm{Na}^{+}, \mathrm{Mg}^{2+}=2 \mathrm{Na}^{+}$, $\mathrm{K}^{+}=\mathrm{Na}^{+}$) or as insoluble. In this section we examine the impact of these assumptions, versus using full thermodynamics. Table 5 displays a summary of this sensitivity test; shown are average concentrations and error metrics for nitrate, ammonium and water with ISORROPIA-II. For all the simulations we used the concentrations of crustals and sodium from the

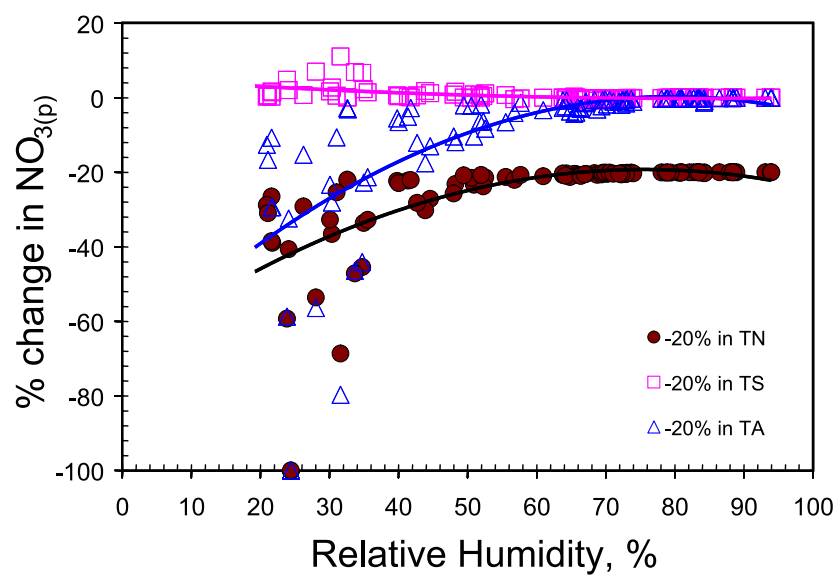

Fig. 7. Response of aerosol nitrate predictions of ISORROPIA-II (stable solution; forward mode) to a $-20 \%$ change in TA, TS and $\mathrm{TN}$ as a function of $\mathrm{RH}$. All data $(\mathrm{CF}=0-\mathrm{CF}=3)$ are used in the dataset.

impactor data. When $\mathrm{Ca}^{2+}, \mathrm{K}^{2+}$ and $\mathrm{Mg}^{2+}$ are treated as insoluble (unreactive), ISORROPIA-II predicts higher, on average, concentrations of ammonium compared to both the equivalent- $\mathrm{Na}$ and explicit treatment, since more sulfate is available to bind with ammonium, and thus the error and bias between predicted and observed ammonium increases for the insoluble approach (Table 5). For particulate nitrate, NME, NMB, MAGE and MB are the lowest when crustals 
Table 4. Sensitivity of volatile species to aerosol precursor concentrations.

\begin{tabular}{|c|c|c|c|c|c|c|c|}
\hline \multicolumn{2}{|c|}{ Statistics } & \multirow{2}{*}{$\begin{array}{r}\mathrm{NH}_{3}(\mathrm{~g}) \\
17.73\end{array}$} & \multirow{2}{*}{$\begin{array}{r}\mathrm{NH}_{4}(p) \\
2.24\end{array}$} & \multirow{2}{*}{$\begin{array}{r}\mathrm{HNO}_{3}(\mathrm{~g}) \\
1.81\end{array}$} & \multirow{2}{*}{$\frac{\mathrm{NO}_{3}(p)}{5.37}$} & \multirow{2}{*}{$\frac{\mathrm{HCl}_{(g)}}{-}$} & \multirow{2}{*}{$\begin{array}{r}\mathrm{Cl}_{(p)} \\
0.25\end{array}$} \\
\hline \multirow{4}{*}{ base case } & mean observed $\left(\mu \mathrm{g} \mathrm{m}^{-3}\right)$ & & & & & & \\
\hline & mean predicted $\left(\mu \mathrm{g} \mathrm{m}^{-3}\right)$ & 16.89 & 3.08 & 1.38 & 5.80 & 0.03 & 0.22 \\
\hline & $\operatorname{NME}(\%)$ & 5.3 & 42.0 & 80.9 & 27.2 & - & 15.6 \\
\hline & NMB (\%) & -4.7 & 37.1 & -23.8 & 8.0 & - & -15.6 \\
\hline \multirow{4}{*}{$(+20 \%) \mathrm{TS}$} & mean predicted $\left(\mu \mathrm{g} \mathrm{m}^{-3}\right)$ & 16.57 & 3.40 & 1.40 & 5.78 & 0.03 & 0.22 \\
\hline & $\operatorname{NME}(\%)$ & 6.9 & 54.6 & 81.9 & 27.5 & - & 15.5 \\
\hline & NMB (\%) & -6.5 & 51.5 & -22.5 & 7.6 & - & -15.5 \\
\hline & $\Delta \mathrm{x}^{*}(\%)$ & -1.91 & 10.50 & 1.68 & -0.40 & - & 0.12 \\
\hline \multirow{4}{*}{$(-20 \%) \mathrm{TS}$} & mean predicted $\left(\mu \mathrm{g} \mathrm{m}^{-3}\right)$ & 17.21 & 2.76 & 1.36 & 5.82 & 0.04 & 0.21 \\
\hline & $\operatorname{NME}(\%)$ & 4.0 & 31.5 & 79.9 & 26.9 & - & 15.7 \\
\hline & NMB $(\%)$ & -2.9 & 23.0 & -25.0 & 8.4 & - & -15.7 \\
\hline & $\Delta \mathrm{x}^{*}(\%)$ & 1.88 & -10.34 & -1.50 & 0.36 & - & -0.15 \\
\hline \multirow{4}{*}{$(+20 \%) \mathrm{TN}$} & mean predicted $\left(\mu \mathrm{g} \mathrm{m}^{-3}\right)$ & 16.53 & 3.44 & 1.46 & 7.15 & 0.03 & 0.22 \\
\hline & $\operatorname{NME}(\%)$ & 7.1 & 56.2 & 83.9 & 41.1 & - & 15.3 \\
\hline & NMB (\%) & -6.8 & 53.4 & -19.0 & 33.1 & - & -15.3 \\
\hline & $\Delta \mathrm{x}^{*}(\%)$ & -2.16 & 11.83 & 6.33 & 23.24 & - & 0.29 \\
\hline \multirow{4}{*}{$(-20 \%) \mathrm{TN}$} & mean predicted $\left(\mu \mathrm{g} \mathrm{m}^{-3}\right)$ & 17.25 & 2.72 & 1.26 & 4.48 & 0.04 & 0.21 \\
\hline & $\operatorname{NME}(\%)$ & 4.1 & 32.3 & 77.0 & 30.5 & - & 15.9 \\
\hline & NMB (\%) & -2.7 & 21.2 & -30.1 & -16.6 & - & -15.9 \\
\hline & $\Delta \mathrm{x}^{*}(\%)$ & 2.11 & -11.61 & -8.22 & -22.80 & - & -0.40 \\
\hline \multirow{4}{*}{$(+20 \%) \mathrm{TA}$} & mean predicted $\left(\mu \mathrm{g} \mathrm{m}^{-3}\right)$ & 20.82 & 3.14 & 1.15 & 6.03 & 0.03 & 0.22 \\
\hline & $\operatorname{NME}(\%)$ & 17.6 & 43.3 & 75.4 & 25.4 & - & 14.8 \\
\hline & $\operatorname{NMB}(\%)$ & 17.5 & 39.9 & -36.5 & 12.3 & - & -14.8 \\
\hline & $\Delta \mathrm{x}^{*}(\%)$ & 23.27 & 2.04 & -16.63 & 3.95 & - & 0.96 \\
\hline \multirow{4}{*}{$(-20 \%) \mathrm{TA}$} & mean predicted $\left(\mu \mathrm{g} \mathrm{m}^{-3}\right)$ & 12.98 & 2.99 & 1.69 & 5.49 & 0.04 & 0.21 \\
\hline & $\operatorname{NME}(\%)$ & 26.7 & 40.3 & 88.9 & 29.9 & - & 16.8 \\
\hline & NMB (\%) & -26.7 & 33.3 & -6.4 & 2.2 & - & -16.8 \\
\hline & $\Delta \mathrm{x}^{*}(\%)$ & -23.13 & -2.80 & 22.83 & -5.42 & - & -1.45 \\
\hline \multirow{4}{*}{$(+20 \%) \mathrm{Na}^{+}, \mathrm{Ca}^{2+}, \mathrm{K}^{+}, \mathrm{Mg}^{2+}$} & mean predicted $\left(\mu \mathrm{g} \mathrm{m}^{-3}\right)$ & 16.94 & 3.02 & 1.39 & 5.77 & 0.04 & 0.21 \\
\hline & $\operatorname{NME}(\%)$ & 5.1 & 40.3 & 80.4 & 27.1 & - & 16.0 \\
\hline & NMB (\%) & -4.4 & 35.0 & -22.5 & 7.6 & - & -16.0 \\
\hline & $\Delta \mathrm{x}^{*}(\%)$ & 0.29 & -1.57 & 1.68 & -0.40 & - & -0.47 \\
\hline
\end{tabular}

${ }^{*} \Delta \mathrm{x}$ denotes the $\%$ change of the mean predicted value of each species compared to the base case prediction.

Table 5. Effect of crustal treatment on predicted concentrations of ammonium, nitrate and water.

\begin{tabular}{lllll}
\hline Property & Treatment of crustals & $\mathrm{NH}_{4(p)}$ & $\mathrm{NO}_{3}(p)$ & $\mathrm{H}_{2} \mathrm{O}_{(\text {liq })}$ \\
\hline mean observed $\left(\mu \mathrm{g} \mathrm{m}^{-3}\right)$ & & 2.24 & 5.37 & - \\
& Insoluble & 3.17 & 5.47 & 13.23 \\
mean predicted $\left(\mu \mathrm{g} \mathrm{m}^{-3}\right)$ & Equivalent Na & 2.77 & 5.61 & 13.09 \\
& ISORROPIA-II & 2.55 & 5.86 & 11.67 \\
& Insoluble & $46.8(41.5)$ & $31.0(1.9)$ & N/A \\
NME $(\mathrm{NMB}),(\%)$ & Equivalent Na & $34.3(23.3)$ & $28.7(4.4)$ & N/A \\
& ISORROPIA-II & $34.0(13.6)$ & $26.2(0.2)$ & N/A \\
\multirow{2}{*}{ MAGE $(\mathrm{MB}), \mu \mathrm{g} \mathrm{m}^{-3}$} & Insoluble & $1.05(0.93)$ & $1.67(0.10)$ & N/A \\
& Equivalent Na & $0.77(0.52)$ & $1.54(0.24)$ & N/A \\
& ISORROPIA-II & $0.76(0.31)$ & $1.41(0.05)$ & N/A \\
\hline
\end{tabular}


are treated explicitly. The changes in NME and NMB among the three crustal treatment approaches are rather small since ammonia is enough to fully neutralize the available nitrate regardless of the treatment of crustals. The difference in nitrate prediction when treating crustals explicitly vs. as equivalent sodium is expected to be large in environments where nonvolatile nitrate $\left(\mathrm{Ca}\left(\mathrm{NO}_{3}\right)_{2}, \mathrm{Mg}\left(\mathrm{NO}_{3}\right)_{2}, \mathrm{KNO}_{3}\right)$ is present in significant amounts (Moya et al., 2002; Jacobson, 1999). In the current dataset, aerosol nitrate is present in the form of ammonium nitrate (due to ammonia-rich environment) and thus replacing crustals with sodium is expected to have a minor effect on predicted nitrate response, primarily from differences in predicted water uptake (Table 5). The equivalent $\mathrm{Na}$ approach predicts aerosol water content which is higher (by $13.5 \%$ ) than the one predicted by the explicit treatment of crustals and very close to the insoluble approach (Table 5). This is attributed to the formation of salts with low solubility (e.g., $\mathrm{CaSO}_{4}$ ) which does not significantly contribute to water uptake. The difference in water content also affects aerosol acidity (i.e. $\mathrm{pH}$ ) and water-soluble species concentration. It should be noted that the differences described in Table 5 between the equivalent $\mathrm{Na}$ and explicit treatment of crustals are the minimum expected considering the large amounts of ammonia in Mexico City which minimizes the effect of replacing crustals with sodium.

\section{Conclusions}

This study focuses on thermodynamical modeling of gasaerosol partitioning sampled during the MILAGRO 2006 campaign in Mexico City. Observations include using hightime resolution measurements of $\mathrm{NH}_{3(\mathrm{~g})}$, volatile nitrate (i.e. $\left.\mathrm{HNO}_{3(\mathrm{~g})}+\mathrm{NH}_{4} \mathrm{NO}_{3}\right), \mathrm{NH}_{4}^{+}, \mathrm{SO}_{4}^{2-}, \mathrm{NO}_{3}^{-}, \mathrm{Na}^{+}, \mathrm{Cl}^{-}, \mathrm{Ca}^{2+}$, $\mathrm{K}^{+}$and $\mathrm{Mg}^{2+}$. Thermodynamic modeling was done using a state-of-the-art aerosol equilibrium model, ISORROPIA-II (Fountoukis and Nenes, 2007).

In agreement with observations, ISORROPIA-II predicts that ammonia $(82.4 \pm 10.1 \%)$ primarily resides in the gas phase, while most of total nitrate $(79.8 \pm 25.5 \%)$ and chloride $(75.3 \pm 29.1 \%)$ resides in the aerosol phase. The mean observed value for $\mathrm{NH}_{3(\mathrm{~g})}$ was $17.73 \mu \mathrm{g} \mathrm{m}^{-3}$ and $5.37 \mu \mathrm{g} \mathrm{m}^{-3}$ for $\mathrm{NO}_{3(p)}$. An excellent agreement between predicted and observed concentration of $\mathrm{NH}_{3(\mathrm{~g})}$ was found with a NME of 5.3\%. Very good agreement was also found for $\mathrm{NO}_{3(p)}(\mathrm{NME}=27.2 \%), \mathrm{NH}_{4(p)}(\mathrm{NME}=37.1 \%)$ and $\mathrm{Cl}_{(p)}(\mathrm{NME}=15.5 \%)$ concentrations for most of the data. Larger discrepancies were seen in predicted $\mathrm{HNO}_{3(\mathrm{~g})}$ since uncertainties in the volatile nitrate measurement $\left(\mathrm{HNO}_{3(\mathrm{~g})}+\mathrm{NH}_{4} \mathrm{NO}_{3}\right)$ are magnified by the high sensitivity of $\mathrm{HNO}_{3(\mathrm{~g})}$ because nitrate partitioned primarily to the aerosol phase. A number of important conclusions arise from this study:
1. Application of ISORROPIA-II is largely successful, suggesting that the assumption of bulk thermodynamic equilibrium is to first order applicable (i.e. to with $20 \%$ of measured concentrations) for Mexico City fine aerosol particulate matter. We suggest that this happens because $i$ ) Mexico City is unusually ammonia-rich, so most of it resides in the gas phase even after equilibration - hence particle acidity is not expected to vary substantially with size (aerosol nitrate is not systematically underpredicted, which further supports that acidity does not vary substantially between submicron particles), $i i$ ) aerosol at T1 is generally aged and its aerosol heterogeneity is expected to be much less, when compared to aerosol collected from downtown (T0).

2. Assuming a particle diameter of $1 \mu \mathrm{m}$, the timescale for thermodynamic equilibrium of semi-volatile species was found to be $27 \pm 19 \mathrm{~min}$ for $\mathrm{HNO}_{3}, 14 \pm 11 \mathrm{~min}$ for $\mathrm{NH}_{3}, 18 \pm 15 \mathrm{~min}$ for $\mathrm{NO}_{3}$ and $15 \pm 13$ min for $\mathrm{NH}_{4}$, on average with a maximum during the night and early morning hours. These timescales are consistent with high-resolution measurements of aerosol nitrate (Hennigan et al., 2008), and with the observation that most of the $\mathrm{PM}_{2.5}$ mass is in the submicron range (Salcedo et al., 2006). Changes in RH and temperature tend to affect equilibration over longer timescales than changes in aerosol precursor concentration.

3. The large temporal variability in RH, $T$, gas- and aerosol-phase species showcases the importance of high-resolution measurements; this also implies that application of an equilibrium model to measurements (bulk or size-resolved) with long integration times is questionable.

4. The scatter in nitrate prediction error $(\sim 30 \%)$ can be attributed to reaction of particles between 2.5 and $10 \mu \mathrm{m}$ diameter with nitrate (the effect of which is not considered in our analysis). If true, this suggests that on average, up to $30 \%$ of the total aerosol nitrate can be associated with particles having diameter larger than $2.5 \mu \mathrm{m}$.

5. At low RH $(<50 \%)$, the stable state (i.e. deliquescence branch) solution of ISORROPIA-II predicted significantly higher concentrations of aerosol nitrate compared to the metastable solution. Further analysis indicates this to be true when $\mathrm{SO}_{4}^{2-} / \mathrm{NO}_{3}^{-}<1$. The opposite was seen (although with a much smaller difference between metastable and stable predictions) when $\mathrm{SO}_{4}^{2-} / \mathrm{NO}_{3}^{-}>1$. This bimodal behavior may be a result of crustal influence, which may at times be diminished by organics that can promote thermodynamically stable water down to very low RH. This can serve as an important constraint for three dimensional air quality models that simulate ambient particle concentrations under conditions characteristic of Mexico City. 
6. The volatile fraction of $\mathrm{PM}_{2.5}$ was found to be mostly sensitive to changes in TN. This suggests that in an ammonia-rich environment, (such as Mexico City) a combined reduction in TS and TN (rather than TA) appears to be most effective in reducing $\mathrm{PM}_{2.5}$ (on a mol per mol basis).

7. Treating crustal species as "equivalent sodium" (or insoluble) has an important impact on predicted aerosol water uptake, nitrate and ammonium, despite the ammonia-rich environment of Mexico City. This suggests that explicit treatment of crustals (when present) is required for accurate predictions of aerosol partitioning and phase state.

8. Concentrations of gas phase $\mathrm{HCl}$ were most likely low (mean predicted value for $\mathrm{HCl}_{(g)}=0.03 \mu \mathrm{g} \mathrm{m}^{-3}$ ), a consequence of having large excess of $\mathrm{NH}_{3(\mathrm{~g})}$ which tends to drive $\mathrm{Cl}^{-}$into the aerosol.

Acknowledgements. $\mathrm{CF}$ and AN acknowledge NOAA (NMRAC000-5-04017) and the EPA (X83234201). AS and RW acknowledge NSF (ATM-0513035). TV acknowledges the NCAR Advanced Study Program. MF acknowledges the Laboratory Directors Research and Development grant at the Lawrence Berkeley National Laboratory. EM and MM acknowledge CONACyT-J51782, PAPIIT-UNAM IN107306. DF and RC acknowledge support from NSF (ATM-0511829). Finally, we would like to thank three anonymous reviewers and the editor for comments that substantially improved the manuscript.

Edited by: S. Madronich

\section{References}

Amundson, N. R., Caboussat, A., He, J. W., Martynenko, A. V., Savarin, V. B., Seinfeld, J. H., and Yoo, K. Y.: A new inorganic atmospheric aerosol phase equilibrium model (UHAERO), Atmos. Chem. Phys., 6, 975-992, 2006,

http://www.atmos-chem-phys.net/6/975/2006/.

Ansari, A. S. and Pandis, S. N.: The effect of metastable equilibrium states on the partitioning of nitrate between the gas and aerosol phases, Atmos. Environ., 34, 157-168, 2000.

Ansari, A. S. and Pandis, S. N.: Prediction of multicomponent inorganic atmospheric aerosol behavior, Atmos. Environ., 33, 745757, 1999a.

Ansari, A. S. and Pandis, S. N.: An analysis of four models predicting the partitioning of semivolatile inorganic aerosol components, Aerosol Sci. Technol., 31, 129-153, 1999b.

Capaldo, K. P., Pilinis, C., and Pandis, S. N.: A computationally efficient hybrid approach for dynamic gas/aerosol transfer in air quality models, Atmos. Environ., 34, 3617-3627, 2000.

Cruz, C. N., Dassios, K. G., and Pandis, S. N.: The effect of dioctyl phthalate films on the ammonium nitrate aerosol evaporation rate, Atmos. Environ., 34, 3897-3905, 2000.

Dassios, K.G., and Pandis, S.N.: The mass accommodation coefficient of ammonium nitrate aerosol, Atmos. Environ., 33, 29933003, 1999.
Day, D. A., Wooldridge, P. J., Dillon, M., Thornton, J. A., and Cohen, R. C.: A Thermal dissociation-laser induced fluorescence instrument for in situ detection of $\mathrm{NO}_{2}$, peroxy(acyl)nitrates, alkyl nitrates, and $\mathrm{HNO}_{3}$, J. Geophys. Res., 107(D5-6), 4046, doi:10.1029/2001JD000779, 2002.

Doran, J. C., Arnott, W. P., Barnard, J. C., Cary, R., Coulter, R., Fast, J. D., Kassianov, E. I., Kleinman, L., Laulainen, N. S., Martin, T., Paredes-Miranda, G., Pekour, M. S., Shaw, W. J., Smith, D. F., Springston, S. R., and Yu, X.-Y.: The T1-T2 study: evolution of aerosol properties downwind of Mexico City, Atmos. Chem. Phys., 7, 1585-1598, 2007,

http://www.atmos-chem-phys.net/7/1585/2007/.

Farmer, D. K., Wooldridge, P. J., and Cohen, R. C.: Thermaldissociation laser induced fluorescence (TD-LIF) as a new technique for measurement of $\mathrm{HNO}_{3}, \Sigma$ Alkyl nitrates, $\Sigma$ peroxy nitrates, and $\mathrm{NO}_{2}$ eddy covariance fluxes, Atmos. Chem. Phys., 6, 3471-3486, 2006, http://www.atmos-chem-phys.net/6/3471/2006/.

Fast, J. D., de Foy, B., Acevedo Rosas, F., Caetano, E., Carmichael, G., Emmons, L., McKenna, D., Mena, M., Skamarock, W., Tie, X., Coulter, R. L., Barnard, J. C., Wiedinmyer, C., and Madronich, S.: A meteorological overview of the MILAGRO field campaigns, Atmos. Chem. Phys., 7, 2233-2257, 2007, http://www.atmos-chem-phys.net/7/2233/2007/.

Fountoukis, C., and Nenes, A.: ISORROPIA II: A computationally efficient thermodynamic equilibrium model for $\mathrm{K}^{+}$. $\mathrm{Ca}^{2+}-\mathrm{Mg}^{2+}-\mathrm{NH}_{4}^{+}-\mathrm{Na}^{+}-\mathrm{SO}_{4}^{2-}-\mathrm{NO}_{3}^{-}-\mathrm{Cl}^{-}-\mathrm{H}_{2} \mathrm{O}$ aerosols, Atmos. Chem. Phys., 7, 4639-4659, 2007,

http://www.atmos-chem-phys.net/7/4639/2007/.

Jacobson, M. Z.: Studying the effect of calcium and magnesium on size-distributed nitrate and ammonium with EQUISOLV II, Atmos. Environ., 33, 3635-3649, 1999.

Heitzenberg, J.: Fine particles in the global troposphere: a review, Tellus 41B, 149-160, 1989.

Hennigan, C. J., Sullivan, A. P., Fountoukis, C. I., Nenes, A., Hecobian, A., Vargas, O., Case, A. T., Hanks, L., Huey, G., Lefer, B. L., and Weber, R. J.: On the Volatility and Production Mechanisms of Newly Formed Nitrate and Water Soluble Organic Aerosol in Mexico City, Atmos. Chem. Phys., 8, 3761-3768, 2008 , http://www.atmos-chem-phys.net/8/3761/2008/.

Malm, W. C., Sisler, J. F., Huffman, D., Eldred, R. A., and Cahill, T. A.: Spatial and seasonal trends in particle concentration and optical extinction in the United States, J. Geophys. Res., 99, 13471370, 1994.

Marcolli, C., Luo, B., and Peter, T.: Mixing of the Organic Aerosol Fractions: Liquids as the Thermodynamically Stable Phases, J. Phys. Chem. A, 108, 2216-2224, 2004.

Martin S. T., Han, J. H., and Hung H. M.: The size effect of hematite and corundum inclusions on the efflorescence relative humidities of aqueous ammonium sulfate particles, Geophys. Res. Lett., 28(13), 2601-2604, 2001.

Meng, Z. Y., Seinfeld, J. H., Saxena, P., and Kim, Y. P.: Atmospheric gas - aerosol equilibrium IV. Thermodynamics of carbonates, Aerosol Sci. Technol., 23, 131-154, 1995.

Metzger, S., Mihalopoulos, N., and Lelieveld, J.: Importance of mineral cations and organics in gas-aerosol partitioning of reactive nitrogen compounds: case study based on MINOS results, Atmos. Chem. Phys., 6, 2549-2567, 2006, 
http://www.atmos-chem-phys.net/6/2549/2006/.

Meng, Z. and Seinfeld, J. H.: Time scales to achieve atmospheric gas aerosol equilibrium for volatile species, Atmos. Environ., 30, 2889-2900, 1996.

Moya, M., Fountoukis, C., Nenes, A., Matías, E., and Grutter, M.: Predicting diurnal variability of fine inorganic aerosols and their gas-phase precursors near downtown Mexico City, Atmos. Chem. Phys. Discuss., 7, 11257-11294, 2007, http://www.atmos-chem-phys-discuss.net/7/11257/2007/.

Moya, M., Grutter, M., and Baez, A.: Diurnal variability of sizedifferentiated inorganic aerosols and their gas-phase precursors during January and February of 2003 near downtown Mexico City, Atmos. Environ., 38, 5651-5661, 2004.

Moya, M., Pandis, S. N., and Jacobson, M. Z.: Is the size distribution of urban aerosols determined by thermodynamic equilibrium? An application to Southern California, Atmos. Environ., 36, 2349-2365, 2002.

Moya, M., Ansari, A. S., and Pandis, S. N.: Partitioning of nitrate and ammonium between the gas and particulate phases during the 1997 IMADA-AVER study in Mexico City, Atmos. Environ., 35, 1791-1804, 2001.

Nowak, J. B., Huey, L. G., Russell, A. G., Tian, D., Neuman, J. A., Orsini, D., Sjostedt, S. J., Sullivan, A. P., Tanner, D. J., Weber, R. J., Nenes, A., Edgerton, E., and Fehsenfeld, F. C.: Analysis of urban gas phase ammonia measurements from the 2002 Atlanta Aerosol Nucleation and Real-Time Characterization Experiment (ANARChE), J. Geophys. Res., 111, D17308, doi:10.1029/2006JD007113, 2006.

Orsini, D. A., Ma, Y., Sullivan, A., Sierau, B., Baumann, K., and Weber, R. J.: Refinements to the particle-into-liquid sampler (PILS) for ground and airborne measurements of water soluble aerosol composition, Atmos. Environ., 37, 1243-1259, 2003.

Pilinis, C., Capaldo, K. P, Nenes, A., and Pandis, S. N.: MADM A New Multicomponent Aerosol Dynamics Model, Aerosol Sci. Technol., 32(5), 482-502, 2000.

Salcedo, D., Onasch, T. B., Dzepina, K., Canagaratna, M. R., Zhang, Q., Huffman, J. A., DeCarlo, P. F., Jayne, J. T., Mortimer, P., Worsnop, D. R., Kolb, C. E., Johnson, K.S., Zuberi, B., Marr, L.C., Volkamer, R., Molina, L. T., Molina, M. J., Cardenas, B., Bernabe, R. M., Marquez, C., Gaffney, J. S., Marley, N. A., Laskin, A., Shutthanandan, V., Xie, Y., Brune, W., Lesher, R., Shirley, T., and Jimenez, J. L., Characterization of ambient aerosols in Mexico City during the MCMA-2003 campaign with Aerosol Mass Spectrometry: results from the CENICA Supersite, Atmos. Chem. Phys., 6, 925-946, 2006, http://www.atmos-chem-phys.net/6/925/2006/.
San Martini, F. M., Dunlea, E. J., Volkamer, R., Onasch, T. B., Jayne, J. T., Canagaratna, M. R., Worsnop, D. R., Kolb, C. E., Shorter, J. H., Herndon, S. C., Zahniser, M. S., Salcedo, D., Dzepina, K., Jimenez, J. L., Ortega, J. M., Johnson, K. S., McRae, G. J., Molina, L. T., and Molina M. J.: Implementation of a Markov Chain Monte Carlo method to inorganic aerosol modeling of observations from the MCMA-2003 campaign Part II: Model application to the CENICA, Pedregal and Santa Ana sites, Atmos. Chem. Phys., 6, 4889-4904, 2006, http://www.atmos-chem-phys.net/6/4889/2006/.

Seinfeld, J. H. and Pandis, S. N.: Atmospheric Chemistry and Physics: From Air Pollution to Climate Change, John Wiley \& Sons, Inc., 558-574, 2006.

Takahama, S., Wittig, A. E., Vayenas, D. V., Davidson, C. I., and Pandis, S. N.: Modeling the diurnal variation of nitrate during the Pittsburgh Air Quality Study, J. Geophys. Res., 109, D16S06, doi:10.1029/2003JD004149, 2004.

Wexler, A. S. and Clegg, S. L.: Atmospheric aerosol models for systems including the ions $\mathrm{H}^{+}, \mathrm{NH}_{4}^{+}, \mathrm{Na}^{+}, \mathrm{SO}_{4}^{2-}$, $\mathrm{NO}_{3}^{-}, \mathrm{Cl}^{-}, \mathrm{Br}^{-}$, and $\mathrm{H}_{2} \mathrm{O}$, J. Geophys. Res., 107, 4207, doi:10.1029/2001JD000451, 2002.

Wexler, A. S. and Seinfeld, J. H.: Second - generation inorganic aerosol model, Atmos. Environ., 25A, 2731-2748, 1991.

Wexler, A. S. and Seinfeld, J. H.: Analysis of aerosol ammonium nitrate: departures from equilibrium during SCAQS, Atmos. Environ., 26A, 579-591, 1992.

Yu, S., Dennis, R., Roselle, S., Nenes, A., Walker, J., Eder, B., Schere, K., Swall, J., and Robarge, W.: An assessment of the ability of three-dimensional air quality models with current thermodynamic equilibrium models to predict aerosol $\mathrm{NO}_{3}^{-}$, J. Geophys. Res., 110, D07S13, doi:10.1029/2004JD004718, 2005.

Zhang, Y., Seigneur, C., Seinfeld, J. H., Jacobson, M., Clegg, S. L., and Binkowski, F. S.: A comparative review of inorganic aerosol thermodynamic equilibrium models: similarities, differences, and their likely causes, Atmos. Environ., 34, 117-137, 2000.

Zhang, J., Chameides, W. L., Weber, R., Cass, G., Orsini, D., Edgerton, E. S., Jongejan, P., and Slanina, J.: An evaluation of the thermodynamic equilibrium assumption for fine particulate composition: Nitrate and ammonium during the 1999 Atlanta Supersite Experiment, J. Geophys. Res., 107, 8414, doi:10.1029/2001JD001592, 2003. 